\begin{tabular}{|c|l|}
\hline Title & Experimental Investigation of the Influence of Moisture on the Bond Behavior of FRP to Concrete Interfaces \\
\hline Author(s) & Dai, Jian-Guo; Y okota, Hiroshi; Iwanami, Mitsuy asu; Kato, Ema \\
\hline Citation & $\begin{array}{l}\text { Journal of Composites for Construction, 146), 834-844 } \\
\text { https://doi.org/10.1061/AASCE)CC.1943-5614.0000142 }\end{array}$ \\
\hline Issue Date & 2010 -11 \\
\hline Doc URL & http://hdl.handle.net/2115/47516 \\
\hline Type & article (author version) \\
\hline File Information & JCC146_834844.pdf \\
\hline
\end{tabular}

Instructions for use 


\title{
Experimental Investigation of the Influence of Moisture on the Bond Behavior of Fibre Reinforced Polymer (FRP) to Concrete Interfaces
}

\author{
Jian-Guo Dai ${ }^{1}$, Hiroshi Yokota $^{2}$, Mitsuyasu Iwanami ${ }^{3}$ and Ema Kato ${ }^{4}$
}

1. Assistant Professor (Corresponding author), Department of Civil and Structural Engineering, The Hong Kong Polytechnic University, Hung Hom, Kowloon, Hong Kong, China, Tel: (852) 27666026, Fax: (852)23346389, E-mail: cejgdai@polyu.edu.hk

2. Professor, Division of Built Environment, Hokkaido University, Sapporo 060-8628, Japan.

3. Senior Researcher, Life Cycle Management Research Center, Port and Airport Research Institute, Yokosuka 239-0826, Japan

4. Senior Researcher, Life Cycle Management Research Center, Port and Airport Research Institute, Yokosuka 239-0826, Japan 


\begin{abstract}
The effects of moisture on the initial and long-term bonding behaviour of fibre reinforced polymer (FRP) sheets-to-concrete interfaces have been investigated by means of a two-year experimental exposure program. The research is focused on the effects of 1) moisture at the time of FRP installation, in this paper termed "construction moisture", consisting of concrete substratum surface moisture and external air moisture, and 2) moisture, in this paper termed "service moisture", which normally varies throughout the service life of concrete. Concrete beams with FRP bonded to their soffits were prepared. Before bonding, concrete substrates were pre-conditioned with different moisture contents and treated with different primers. The FRP bonded concrete beams were then cured under different humidity conditions, before being subjected to combined wet/dry and thermal cycling regimes to accelerate the exposure effects. Adhesives with different elastic modulus were used to investigate the long-term durability of each adhesive, when subjected to accelerated wet/dry cycling. Pull-off tests and bending tests were conducted at the beginning of the cycling and then again, after 8 months, 14 months and 2 years of exposure so as to evaluate the tensile and shear performance of the FRP-to-concrete interfaces. It was found that the effect of the concrete substrate moisture content on short-term interfacial bond performance could be eliminated if an appropriate primer was used. All FRP-to-concrete bonded joints failed at the interface between the primer and concrete after exposure while those not exposed usually failed within the concrete substrate. After exposure to an environment of accelerated wet/dry cycles, it was also found that the interfacial tensile bond strength degraded asymptotically with the exposure time while the flexural capacity of the FRP sheet bonded plain concrete beams even increased. The mechanism behind the above, which is an apparently contradictory phenomenon, is discussed.
\end{abstract}

KEYWORDS: FRP, Concrete, Bond, Moisture, Long-term bond durability, Wet/dry cycling 


\section{INTRODUCTION}

The strengthening of reinforced concrete (RC) structures using externally bonded fiber reinforced polymer (FRP) systems has gained widespread acceptance in recent years. This strengthening technique is particularly attractive for reinforced concrete (RC) structures in marine environments, since FRP composites are non-corrosive. In addition, externally bonded FRP composites can act as a protective layer to internal reinforcement and concrete and prevent such as chloride ion penetration and that of other aggressive agents. However, a significant obstacle to the wider adoption of externally bonded FRP systems in marine RC structures is uncertainty regarding the long-term performance. FRP-strengthened RC structures (e.g. port structures) in marine environments are usually subjected to adverse environmental attacks, such as concentrated concrete surface moisture, external moisture in the air during the bonding of FRP and frequent wet/dry cycles during service life. While the effect of moisture on the performance of FRP composites is one of the most widely studied durability issues (Bank and Gentry 1995), there is only limited understanding of the effect of moisture on the long-term durability of FRP-strengthened RC structures.

FRP to concrete bond behaviour has a direct influence on the failure mode of an FRP-strengthened $\mathrm{RC}$ structure. This is particularly true for flexurally- and shear-strengthened RC beams (Teng et al. 2002). In order to establish a safe and economical approach to the durability design of FRP-strengthened RC structures to suit a specific environment, a clearer understanding is necessary, of the durability of the FRP-to-concrete bond itself (including the adhesive) for the specific environment.

Very little research has been conducted to investigate how the presence of moisture influences the initial bond performance of FRP-to-concrete interfaces. Based upon their tests, Myers and Ekenel (1999) recommended maximum allowable limits of $4.3 \%, 82 \%$, and $30.5^{\circ} \mathrm{C}\left(90^{\circ} \mathrm{F}\right)$ for concrete surface moisture content, air relative humidity, and air temperature, respectively, when bonding FRP to concrete. Wan et al. (2006) reported that the presence of water at the concrete substrate level decreases the bond strength between FRP and the substrate. Karbhari and Navada (2008), however, reported that merely a moist substrate (note: in the study, the surface moisture content of concrete was set at $2.5 \%$ by spraying water onto the surface, 30 minutes prior to FRP composite application) is even more detrimental than a saturated substrate (note: the surface moisture content of concrete was about 5-6\% and caused by immersing the specimens in water for 48 hours prior to application of 
the FRP composites).

A variety of exposure schemes have been adopted for investigating the effects of moisture on the long-term bond performance of FRP-to-concrete interfaces, including that of wet/dry (WD) cycling using salt water (Chajes et al. 1995; Toutanji and Gómez 1997; Mukhopadhyaya et al. 1998; Sen et al. 1999; Almusallam 2006), WD cycling using a sodium hydroxide solution (Davalos et al. 2005; Almusallam 2006), WD cycling using fresh water (Leung et al. 2001; Ouyang 2007; Almusallam 2006), fresh water immersion (Karbhari and Zhao, 1998), salt water immersion (Karbhari and Zhao 1998; Leung et al. 2001), constant moisture (Grace and Singh 2005; Au and Büyüköztürk 2006), and natural outdoor exposure (Sen et al. 1999; Almusallam 2006; Far et al. 2008).

Among the above accelerated exposure schemes, the WD cycling scheme has been most frequently used to accelerate the moisture-induced bond degradation of FRP-to-concrete interfaces (Chajes 1995; Sen et al. 1999). A freeze/thaw (FT) cycle using salt water is another moisture related exposure scheme, has been adopted by some researchers to investigate the effects of simultaneous WD and thermal cycling on the long-term bond performance of FRP-to-concrete interfaces in cold regions (Chajes et al. 1995; Karbhari and Zhao, 1998; Mukhopadhyaya et al. 1998; Green et al. 2000; Grace and Singh 2005; Jia et al. 2005; Almusallam 2006). So far little research has been conducted to investigate the synergistic effects of WD and temperature cycles on the bond durability of FRP-to-concrete interfaces in subtropical regions. Such regions are likewise characterized by frequent WD cycling and seasonal temperature change. Hong Kong, Southern China and many other parts of the world are such climatic regions. The study presented in this paper thus focuses on the short and long term bond behaviour of FRP-to-concrete interfaces that are already moist during bond construction (construction moisture), due to such as surface moisture within concrete substrates and external air humidity, and which experience changing external moisture conditions during the service life of the strengthened structure (service moisture).

The effects of moisture on the short- and long-term behaviour of FRP-strengthened concrete systems have been studied using either a strength-based approach or a fracture mechanics-based approach. In the strength-based approach, bond degradation is evaluated by measuring the interfacial tensile bond strength using pull-off tests (Sen et al. 1999), the interfacial shear bond strength with torsional tests (Sen et al. 1999) or single lap shear tests (Mukhopadhyaya et al. 1998), and by tests of the flexural capacity and ductility of FRP bonded plain concrete/RC beams (Chajes et al. 1995; Toutanji and 
Gómez 1997; Leung et al. 2001; Grace and Singh 2005; Almusallam 2006; Far et al. 2008). The change in long-term bond strength has been reported to vary between a $21 \%$ increase and a $40 \%$ decrease, when compared to the results for specimens not exposed to moisture. Chajes et al. (1995) and Karbhari and Zhao (1998) also reported that Glass FRP (GFRP) bonded concrete specimens degraded to a greater extent than Carbon FRP (CFRP) based specimens under the influence of moisture although the debonding between the FRP and the concrete substrate and not the fracture of the FRP composite was observed as the dominating failure mechanism. In the tests of Toutanji and Gómez (1997), Sen et al. (1999) and Far et al. (2008), the FRP bonded concrete systems were found to deteriorate to different degrees under the influence of moisture, when different epoxy adhesives were used, but no discussion were given on the corresponding mechanisms. It should be noted that the above-mentioned strength deterioration may reflect the effects of many factors and not only the characteristics of the bond itself, such as: 1) the effect of the dimensions of FRP bonded concrete joints/RC beams used in the tests and 2) the stiffness of the FRP reinforcement and the steel reinforcement ratio. As a result, most of these test results cannot be generalized and cannot therefore serve as the basis for the development of a reliable approach to practical durability design.

In the fracture mechanics-based approach, bond degradation is usually evaluated in terms of the interfacial fracture toughness through double cantilever beam tests (Davalos, 2005), peeling tests (Au and Büyüköztürk 2006; Ouyang 2007) or shear bond tests (Ouyang 2007). Compared to bond strength, the interfacial fracture toughness appears to be a better indicator of the extent of bond degradation, because it excludes the effects of material stiffness and member dimensions. A drawback of this approach, however, is the difficulty in directly implementing interfacial fracture toughness into practical structural durability designs, as this value is usually derived using the linear fracture mechanics discipline.

The literature review presented above reveals that current understanding of the short- and long-term durability of FRP-to-concrete bondline under moisture is still limited. In particular, there is very little long-term exposure data on the fundamental mechanical properties of FRP-to-concrete bonded interfaces as affected by local climatic conditions. In the study presented in this paper, a two-year experimental investigation was conducted to examine the effects of moisture on the short- and long-term tensile and shear bond performance of FRP-to-concrete interfaces, these two properties being the two most fundamental to the design and monitoring of bond performance in engineering practice. In the test programme, coupled thermal and moisture action was applied to accelerate the 
moisture exposure but no freeze and thaw cycles were taken into account. The objectives were to achieve a good understanding of the mechanisms of the bond degradation of FRP-to-concrete interfaces subjected to both short- and long-term moisture conditions and to also provide a solid benchmark database for further development of appropriate practical durability design models for bonds subjected to moist conditions in service.

\section{EXPERIMENTAL PROGRAM}

\section{Test specimens}

Two types of test, bending tests (Fig.1) and pull-off bond tests (Fig.2), were conducted to evaluate the shear and tensile bond performance of FRP-to-concrete interfaces. In total, 56 specimens were tested. Of these specimens, 48 plain concrete beams, strengthened with soffit FRP sheets were prepared for the bending tests. 16 different combinations of moisture content, primer, adhesive, curing air humidity and exposure duration were examined. Each of these 16 specimens was triplicated. 8 further specimens were prepared for tensile pull-off bond tests. Four tensile pull-off bond tests were carried out for each beam to obtain the average tensile bond strength (see Fig.2). All concrete had a water-cement ratio $(\mathrm{W} / \mathrm{C})$ of 0.5 , and a fine-to-coarse aggregate ratio of 0.49 . After placing, the concrete was cured for one month and reached a compressive strength of $33.7 \mathrm{MPa}$ at the time of testing. The specimens were divided into two series: Group A and Group B as summarized in Table 1. Group A specimens were tested for short term moisture effects on bond performance, and Group B specimens were tested for long-term moisture effects. The test variables included pre-conditioned concrete substrate moisture content (dry and wet) at the time of FRP bonding, relative air humidity (R.H) (40\% and 90\%) during the FRP composite curing, adhesive primer type (normal and hydrophilic), bonding adhesive type (normal and ductile), and exposure duration (not exposed, 8 months, 14 months and 2 years).

\section{Materials and Installation Process}

Unlike the dry carbon fibre sheet, popularly adopted in a wet lay-up system, a new type of carbon FRP sheet, the carbon strand sheet (CSS) (see Fig.3), was used in the tests. The CSS is formed from 1.0 2.0 mm diameter circular FRP micro-bars, formed by pultrusion in which continuous carbon fibre strands are impregnated with an epoxy resin. The micro-bars are then properly spaced and aligned into sheet form, using transverse threads for convenient handling and deployment. The 
tensile stiffness of the formed sheet, per unit width, can be adjusted according to design requirements. The use of CFRP micro-bars instead of dry fibre sheets shortens the construction time required for the wet lay-up process and eliminates FRP imperfections. It also leads to better bonding between externally bonded reinforcement and concrete, because any air voids entrapped in the epoxy adhesive can be easily removed. Test results show that the bond strength between FRP and concrete is greater for FRP micro-bars than for FRP plates (Kobayashi et al. 2009) and for wet lay-up FRP sheets (Dai et al. 2009). The main reason is that the use of FRP micro-bars produces a larger FRP adhesive bond area and a larger effective bond length. These features enable a more efficient bond force transfer (Dai et al 2009). Table 2 presents the mechanical properties of the CSS.

Figure 4 is a schematic of the cross sections of the bond between FRP and concrete, for dry carbon fiber sheets and CSS, respectively. It is noted that the bonding processes for the two types of sheet materials are approximately the same. A layer of primer is placed next to the concrete substrate. The difference between the two systems lies only in the FRP matrix. In the wet lay-up system, epoxy tends to be used as the saturation resin and at the same time serves as bonding adhesive, while in the CSS system the stickier epoxy putty is used. The latter enables easier stabilization of the concrete surface. Epoxy putty has a further function in the wet lay-up system, in that it can be applied to smooth any unevenness in the concrete substrate surface. However, such a process is not necessary in the CSS system, since its own matrix is also the epoxy putty. It is considered that the test results on the durability of interface bond, based upon the CSS system, should also be relevant to the wet lay-up system, since the interfacial debonding, which occurs within a thin concrete layer beneath the primer, rather than within the FRP composite itself, is a dominating mechanism for both CSS and wet lay-up systems (Dai et al. 2009). Based on the above discussion, below, FRP formed through the CSS system is referred to as an "FRP composite"; the interface between the epoxy putty-stabilized CSS and concrete substrate is known as an "FRP-to-concrete interface"; concrete beams strengthened with a CSS system are termed "FRP bonded concrete beams"

Before being bonded with FRP composites, the concrete substrate surfaces were pre-conditioned, each with a different moisture content to simulate the different possible construction conditions encountered in a moist environment. Two extreme cases were studied. One case involved a dry concrete surface with an average surface moisture content of just below $4.2 \%$. The other had a wet concrete surface, prepared by immersing the specimens into sea water for three days. The surface water was removed, immediately before FRP composite bonding, by lightly brushing the concrete 
surface using a cotton cloth. In these circumstances the measured average concrete surface moisture content was about $9.0 \%$. Two different types of primer: a conventional type, FP-NS, and a hydrophobic type, FP-WE7, were used for the dry and wet substrate, respectively. The primer FP-WE7 was invented by Saito in 1996 and consists of a liquid epoxy resin, a hydrophobic polyamine compound, a thixotropic agent and a silane coupling agent. Tensile pull-off tests verified the effectiveness of such a primer to achieve a good bond with the wet concrete substrate (Saito 1996). However the influence of this type of primer on the short- and long-term shear bond force transfer between FRP and concrete in moist environments is not yet understood.

A soft bonding adhesive can improve short-term shear bond force transfer between FRP and concrete (Dai et al. 2005). To see whether the soft bonding adhesive can better cope with temperature induced stresses and moisture conditions at FRP-to-concrete interfaces, two types of adhesives (FE-Z and CN-100) with different elastic moduli were used (see Fig.5). FE-Z is a popularly used type of epoxy putty with linear elastic properties. It has an elastic modulus of $2.41 \mathrm{GPa}$. CN-100 is a non-linear type of epoxy with an elastic modulus of $0.39 \mathrm{GPa}$. It should be noted that the epoxy $\mathrm{CN}-100$ was used only as a bonding adhesive with a thickness of $0.5 \mathrm{~mm}$ between the primer and the FRP while the FRP matrix remained as the epoxy putty FE-Z so as not to alter the FRP composite mechanical properties thus enabling focus on the FRP-to-concrete interfaces.

\section{Moisture condition during the curing of bonded FRP composites}

Two sets of curing conditions were adopted after the FRP composites had been bonded onto the concrete surfaces. One comprised ambient laboratory conditions, with an average temperature of $10^{\circ} \mathrm{C}$ and air relative humidity (R.H) of $48 \%$. The other consisted of well-controlled chamber conditions with a constant temperature of $10^{\circ} \mathrm{C}$ and an R.H. of $90 \%$. The curing period was two weeks in both cases.

\section{Exposure scheme}

As references, tensile pull-off and bending tests were conducted after curing on Series A specimens and some Series B specimens to evaluate the effects of moisture on the short-term bond performance of FRP-to-concrete interfaces and to obtain the initial bond performance before exposure to accelerated weathering regimes. The remaining Series B specimens were placed in an exposure pool and subjected to accelerated wet/dry cycling for 8 months, 14 months, and 2 years. Each wet/dry 
cycle consisted of a 4-day immersion in $60^{\circ} \mathrm{C}$ sea water and a 3-day exposure to dry air exposure in a laboratory. An electric fan was used to dry the specimens more efficiently. The higher temperature $\left(60^{\circ} \mathrm{C}\right)$ adopted was expected to accelerate the diffusion of moisture into the concrete. In the meantime, the purpose of combining thermal and moisture cycling was to achieve closer simulation of real exposure conditions, where changes of temperature and humidity are usually coupled.

\section{Investigation by Microscope of FRP-to-concrete interfaces}

Observations by microscope were conducted to see if the exposure had induced any physical damage to the FRP-to-concrete interfaces. Part of the section shown in Fig.4 was cut from an FRP bonded concrete beam, and its surface then carefully polished using several sheets of abrasive paper with a gradually increasing fineness. Such work had to be carefully conducted to avoid introducing additional damage to the FRP-to-concrete interface.

\section{RESULTS AND DISCUSSION}

\section{Tensile pull-off tests on beams not exposed and beams exposed}

Tensile pull-off tests are popularly used for evaluating the adhesion of a coating to a rigid substrate, such as metal, concrete or wood. Such tests are frequently used to evaluate in-situ bond quality. The pull-off bond strength is also an important bond performance parameter for FRP-to-concrete interfaces. Fig. 6 shows the tensile pull-off bond strength of FRP-to-concrete interfaces which have undergone different periods of exposure. Two series of specimens were tested. One series had dry concrete substrates treated with a normal primer FP-NS (see Series B-1-× in Table 1). The other had wet concrete substrates treated with a hydrophobic primer FP-WE7 (see Series B-6-× in Table 1). It was clearly seen that, before exposure, both series exhibited similar interfacial tensile bond strength in spite of each having different initial moisture content. This indicates the effectiveness of hydrophobic primer for wet concrete substrates. Hence a reasonable conclusion is that the initial moisture content of a concrete substrate may not be a critical issue, providing an appropriate primer material is applied. Usually, the suitability of a primer for use with a wet substrate depends largely on its water absorption properties. If the primer is hydrophilic, the primer will absorb water before the concrete has been sufficiently cured, leading to the loss of strength and stiffness as well as bond strength between the primer and the concrete substrates. A hydrophobic primer, therefore, is 
necessary in cases where the concrete substrate moisture content is of concern. However, the use of the hydrophobic primer FP-WE7 was not able to prevent the interfacial tensile bond strength loss after a period of wet/dry cycling. There was a clear and rapid decrease in the tensile bond strength of FRP-to-concrete interfaces after 8 months of exposure, regardless of the type of primer used and the moisture content in the concrete substrates (see Fig.6). However, further exposure of up to two years, did not lead to greater reductions in the interfacial tensile bond strength.

Figure 7 illustrates the planes of failure of FRP-to-concrete interfaces, as viewed from the FRP side, after the pull-off tests. A significant change in the bond failure mode was observed after accelerated wet/dry cycling. This corresponded with the tensile bond strength loss. Before exposure, failure was observed in the concrete substrate with slight differences in the failure modes caused by different moisture conditions (see the left two photographs in Fig.7). After exposure, however, failure was observed mainly at the primer-to-concrete interface. Au and Büyüköztürk (2006) and Silva and Biscasia (2008) reported similar bond failure modes. Ouyang and Wan (2006) and Au and Büyüköztürk (2006) assumed that the moisture concentration in the concrete substrate next to the primer layer was a major causal factor in the deterioration of the interfacial bond. Thus the moisture content in that part of the concrete substrates correlates with Mode I and/or Mode II interfacial fracture toughness. However, the interfacial bond strength loss may not directly correlate with the moisture content of the concrete substrate. During the wet and dry exposure regime, moisture would have penetrated and diffused into the polymeric components, leading to their plasticization, loss of stiffness and strength. However, the moisture content, in the concrete substrate, during wet and dry exposure is reversible while the degradation of the bondline is irreversible.

\section{Observations by microscope}

Bi-material adhesion involves many mechanisms such as adsorption, mechanical interlocking, diffusion, and electrostatic mechanisms (Ouyang 2007). To date, the issue of how moisture absorption or wet/dry cycling influences each single mechanism remains unclear. But it can be concluded that the primer-to-concrete interface is the weakest link, after wet/dry cycling, based on failure modes shown in Fig.7. In order to fully observe what has occurred, observations by microscope were made of FRP-to-concrete interfaces after exposure but before the tensile pull-off tests took place. Figs. 8.a and 8.b present the typical bondlines observed before and after exposure. From the figures, it is reasonable to extrapolate that the decrease in tensile pull-off bond strength was 
caused by the formation of such as interfacial micro-cracks. The material incompatibility between the primer and the concrete substrate under wet/dry cycling is likely to be a major factor leading to such cracks. The incompatibility was mainly due to a sudden change of mechanical and thermal properties and diffusivity of the two materials at the bonded interface. The issue of how to minimize the materials incompatibility, by optimizing the bonding materials, seems to be the key to solving the bond durability problem. In addition, solutions are needed to capture such micro-level damage before it culminates in more serious damage and severe failure. Such a solution could then be correlated with macro mechanical bond behaviour.

Effects of moisture at the time of FRP installation (construction moisture) on the short-term shear bond performance of FRP-to-concrete interfaces

Bending tests were conducted on 21 FRP bonded pre-conditioned concrete beams (Group A in Table 1) to evaluate the effects of construction moisture (concrete surface moisture and air humidity for curing FRP composite) and the primer and adhesive on the short-term shear bond performance of FRP-to-concrete interfaces. All beams failed due to debonding between the FRP composite and the concrete substrate. Two debonding failure modes were observed. One consisted of intermediate crack-induced debonding (IC debonding) (see Fig.9.a). The other consisted of critical diagonal crack-induced debonding (CDC debonding) (see Fig.9.b). The failure modes of all beams are summarized in Table 1. In general, CDC debonding occurred at higher load levels than IC debonding.

Three types of interfacial failure have been identified as shown in Fig.10: (A) failure in the concrete substrate (see Fig. 10.a); (B) failure in a thin mortar layer of the concrete substrate (see Figs.10.b and 10.c); and (C) failure at the primer to adhesive interface (see Figs.10.d and 10.e). As summarised in Table 1, if the concrete substrate was dry and a normal primer was applied, failure mode "A" was observed, regardless of the curing air humidity (Series B-1-x and B-5-x in Table 1). However, if a hydropholic primer was used on a dry concrete substrate, in addition to failure mode "A"(see Specimen B-2-1 in Table 1), failure mode C was observed in Specimens B-2-2 and B-2-3 even though the bond between primer and adhesive is usually believed to be stronger than that between primer and concrete substrate. This phenomenon can be interpreted by suggesting that a hydrophobic primer achieves a better bond performance with concrete substrates, thus making the adhesive-to-primer interface appear to be a relatively weak link. Compared with the specimens in the 
B-1 series, for which the normal primer was used, Specimens B-2-2 and B-2-3 in fact exhibited no decrease in their flexural capacity in spite of the debonding failure at the adhesive to primer interface. The beam B-2-1, on which the hydrophobic primer was used but on which the primer-to-adhesive interface failure did not occur, exhibited an even higher flexural capacity, hence implying that the hydrophobic primer was appropriate for both dry and wet concrete substrates.

However, and in contrast, when the concrete substrates were wet failure mode "B" was observed overwhemlingly, regardless of the type of primer used (see Sereis B-3-x, B-4-x and B-6-x in Table 1). A possible reason for such a failure is that the penetration of both types of primer into wet concrete substrates was, in fact, superficial. The hydrophobic primer proved to have good compatibility with a wet concrete substrate since, as mentioned earlier, the hydrophobic polyamine compound in the primer serves as a curing agent or hardener for the liquid epoxy resin and the hydrophobic nature of this curing agent renders the primer hydrophobic and prevents the primer coated on the wet concrete surface from absorbing water. When the coated primer absorbs water, the properties of the primer film deteriorate after curing, preventing sufficient adhesion of the FRP sheets attached thereon (Saito 1996). However, the hydrophobicity of the primer could enhance the surface to surface contact without enhancing the diffusion of the primer into and the interlocking with the nearly saturated substrate. As discussed in the next section, enhanced surface contact could avoid a loss of short-term, rather than long-term, interfacial shear bond strength between FRP composites and wet concrete substrates. When the concrete substrates were wet, failure at the primer-to-adhesive interface was also observed in Series B-7-x, for which a soft bonding adhesive and a hydrophobic primer were used. However, neither did this failure mode lead to a decrease in the flexural capacity of FRP bonded concrete beams (Table 1).

Figures 11.a to 11.e present the effects of concrete surface moisture and air moisture at the time of FRP installation, and of the primer and adhesive on the bending load versus mid-span deflection curves of FRP bonded concrete beams not exposed to accelerated weathering. In the figures, three identical specimens are presented, to illustrate the degree of the experimental scatter, in each test series. Except for Series B-3-× and B-7-× specimens, all others achieved approximately similar flexural capacities and ultimate deformations. When the concrete substrates were dry, high R.H. curing led to a slight decrease in flexural capacity (see Series B-1-× and B-5-× in Fig.11.a). However, when the concrete substrate was wet, high R.H curing led to a slight increase in flexural capacity (see Series B-4-× and B-6-× in Fig.11.b). Since the flexural response of FRP bonded plain concrete beams 
directly reflects the FRP-to-concrete interface shear bond performance, it can be concluded that R.H curing values varying from $48 \%$ to $90 \%$, have only a marginal effect on the shear bond performance of FRP-to-concrete interfaces. The application of the normal type of primer onto a wet substrate caused about a 20\% loss of flexural capacity (see Series B-1-× and B-3-× in Fig.11.c). The hydrophobic primer, FP-WE7, performed well regardless of whether the concrete substrate was dry or wet (see Series B-2-× and B-6-× in Fig.11.d).

Once a primer has been appropriately selected, the most significant factor influencing the shear bond strength of the FRP-to-concrete interfaces seems to be the elastic modulus of the bonding adhesives. Two specimens in Series B-7-× (see Fig.11.e), in which the adhesive CN-100 with a low elastic modulus was used, achieved a flexural capacity about 45\% greater than that of specimens for which a normal adhesive had been used (Series B-4- $\times$ and B-7-x in Fig.11.e) even though the initial concrete substrate was wet. However, it was also found that one Series B-7-× specimen failed due to debonding at the primer-to-adhesive interface, prior to failure in the concrete substrate. Such a failure mode was never observed in the tensile pull-off tests. Therefore, the multilayer structure of the FRP-to-concrete interface induces different failure paths for the cases of tension and shear, particularly when different types of concrete substrate, primer and bonding adhesive are used. A combination of tensile pull-off tests and shear bond tests is deemed necessary, therefore, for an overall evaluation of the bond performance of FRP-to-concrete interfaces.

\section{Effects of moisture during service life (wet/dry cycles) on the long-term shear bond performance of FRP-to-concrete interfaces.}

Figure 12 presents the bending load versus mid-span deflection curves of all those FRP bonded concrete beams that experienced different periods of wet/dry cycling. Only one test in each series is illustrated in Fig.12, as each set of three beams with identical testing parameters all exhibited similar levels of flexural performance, as indicated in Table 1. The ascending linear sections of all the curves were not influenced by wet/dry cycling. This is reasonable because the strength and stiffness of the concrete itself is hardly influenced by a regime of wet/dry cycling. Following the cracking of concrete, however, the load-deflection curves reflect directly the shear bond performance of the FRP-to-concrete interfaces.

It is shown for three test series, B-1-×, B-6-× and B-7-×, after exposure, the bending load vs. 
mid-span deflection curves, exhibited two different behavior patterns. When the normal bonding adhesive FE-Z, with an elastic modulus of $2.41 \mathrm{GPa}$, was used, both the flexural capacity and ductility increased noticeably after 8 and 14 months of exposure (see Figs. 12.a and 12.b). Further exposure to 24 months led to a slight decrease in flexural capacity. But the values were still higher than those of the reference beams not exposed to weathering. As observed in the tensile pull-off tests, all the exposed FRP bonded concrete beams failed by debonding at the primer-to-concrete interface (see Figs 13.a to 13.c). After the bending tests, it was found that almost no concrete was attached to the peeled off FRP. However, an important difference was noted between the tensile pull-off test and bending test results. There was no decrease in the flexural capacity of the FRP bonded concrete beams after the long-term accelerated wet/dry cycling, but there was a decrease in pull-off strength. Two mechanisms are considered responsible for the difference. One is that the formation of micro interfacial cracks, leads to the decrease of the interfacial pull-off bond strength causing a degradation of interfacial shear bond stiffness. Another is degradation of the shear stiffness of the bonding adhesives observed as a result of the wet/dry cycling. Although these two are symptoms of interfacial deterioration and reduced the pull off strength, the existence of both, could lead to an increase in the effective bond length of FRP-to-concrete interfaces and consequently improved the global shear force transfer capacity along the bond interfaces (Dai et al. 2002).

Obviously, the time and exposure-dependent performance of the resins used is the key factor influencing the long-term bond performance of FRP-to-concrete interfaces. Far et al. (2007) chose three different types of adhesives in their exposure tests of CFRP-strengthened reinforced concrete (RC) elements in salt and moisture conditions. They did not observe any decrease in the strength of CFRP-strengthened RC elements although they found a decrease in the tensile strength of the adhesives with exposure duration. They also concluded that those adhesives possessing inferior mechanical properties achieved higher failure loads for the CFRP-strengthened RC elements since viscous adhesives with enough strength can more effectively distribute concentrated interfacial stresses as they can deform under higher loads.

When the low elastic modulus adhesive $\mathrm{CN}-100$ was used, the flexural capacity of the not exposed FRP bonded concrete beams was about $27 \mathrm{kN}$, a value much higher than that of the not exposed beams in the B-1-× series, in which the normal adhesive FE-Z had been used. Nevertheless, after wet/dry cycling the flexural capacity decreased monotonically with increase of exposure duration (see Fig.12.c). Therefore, if the initial shear bond stiffness had been low, further decrease in its value, 
beyond a certain threshold, may eventually cause overall degradation of structural performance, affecting both pull off strength and bending capacity.

Of course, the glass transition temperature, $\mathrm{T}_{\mathrm{g}}$, of the adhesive should be borne in mind when interpreting the degradation of an adhesive bondline after an accelerated exposure test in which a high exposure temperature is deployed. The conventional adhesive FE-Z (after hardening) used in this study possessed a glass transition point $\mathrm{T}_{\mathrm{g}}$ of more than $60^{\circ} \mathrm{C}$ according to the manufacturer's data. The epoxy resin $\mathrm{CN}-100$ was a new type of adhesive and had a lower elastic modulus but much higher ductility compared to FE-Z as reported previously. The $\mathrm{T}_{\mathrm{g}}$ of $\mathrm{CN}-100$ was not available in the manufacturer's data but is believed to be lower than that of FE-Z because a lower elastic modulus usually corresponds to a lower $\mathrm{T}_{\mathrm{g}}$. Under the current accelerated exposure scheme, an exposure test temperature that approached or was even higher than the $T_{g}$ of the adhesives concerned was used to speed up the deterioration. The cross-linking reactions of resins might have restarted during the exposure test and led to a modified structure for the adhesive. As a result, the mechanical properties of the adhesives might have degraded at a much faster rate, which may be significantly different from that which would occur in a field exposure situation. The accelerated exposure test can help to understand how the FRP-to-concrete interface behaves, once deterioration of the adhesive bondline has occurred under a combined thermal and wet/dry cyclic exposure. The issue, however, of how to correlate the degradation of FRP-to-concrete interfaces under an accelerated exposure scheme, involving elevated temperatures, with the degradation which actually occurs in local climate conditions needs further study.

Figure.14 summarizes the change in flexural capacity and specimen ultimate deformation with exposure time for the three test series (B-1-×, B-6-× and B-7-×), described above. The figure shows clearly how overall flexural performance of the FRP bonded plain concrete beams is influenced by the wet/dry cycling, Clearly, two significant and different tendencies can be found when hard and soft adhesives are used. In Series B-1-× and B-6-×, respectively, both the strength and ductility of the FRP bonded plain concrete beams showed first an increasing and then a decreasing tendency. In the test series B-7-×, however, flexural capacity exhibited a consistent decreasing tendency under the exposure cycles, while ductility showed no significant change. It seems obvious that wet/dry cycling significantly influences the shear bond properties of FRP-to-concrete interfaces and results in changes of overall stiffness, strength and ductility of FRP bonded concrete beams. 
The test program, described above, has provided essential data on the long-term bond performance of FRP-to-concrete interfaces under combined thermal and wet/dry cyclic regime and enables further understanding of the degradation mechanisms. To explain and quantify the complex changes discussed above, however, the development of a generic exposure related interfacial bond-slip model is required for predicting the bond durability of FRP-strengthened RC concrete members with the assistance of finite element modeling. Such work is already the subject of an ongoing research project led by the first author and will be reported in the near future.

\section{CONCLUSIONS}

Based upon a two-year exposure program, in which the effects of the presence of moisture both during service life and at the time of FRP installation on the short- and long-term bond performance of FRP -to-concrete interfaces were studied, the following conclusions can be drawn :

(1) Different air curing RH values up to $90 \%$ had a marginal effect only on the bond performance of FRP-to-concrete interfaces.

(2) Surface moisture at concrete substrates during the installation of FRP composites adversely influenced the bond performance of FRP-to-concrete interfaces. However, these adverse effects could be eliminated if a hydrophobic type of primer was used.

(3) After exposure to accelerated wet/dry cycling the bond failure of FRP-to-concrete interfaces always occurred at the primer-to-concrete interface and not within the concrete substrate. In contrast the specimens not exposed to wet/dry cycling bond failure always occurred in a very thin mortar layer of the concrete substrate regardless of the type of primer used, as long as the substrate was wet.

(4) Observations by microscope indicated that wet/dry cycling led to the formation of micro-cracks at the primer-to-concrete interface. As a result, the interfacial tensile strength degraded significantly but seemed to approach to a stable value, asymptotically, during exposure.

(5) With increase in the number of wet/dry cycles, depending upon the type of the bonding adhesive used as well as the exposure duration, and unlike the interfacial tensile strength, the global interfacial shear bond strength, in FRP composite bonded concrete beams, exhibited either a decrease or an increase although the local bond stiffness degraded monotonically with the increase of exposure time. Different threshold values may exist for the number of wet/dry cycles beyond which the global structural performance of FRP-strengthened concrete beams starts to degrade, when different adhesives are used. To explain this complexity, a good understanding of 
the exposure-dependent local bond-slip behavior of the FRP-to-concrete interfaces needs to be developed, so as to correlate the local bond behavior with the overall structural performance based on a generic finite element model.

(6) A loss of tensile bond strength due to moisture, evidenced by tensile pull-off tests, may not necessarily reflect a loss of shear bond transfer capacity along the FRP-to-concrete interfaces, since the former is particularly sensitive to a local weakness while the latter takes more account of the whole interface. Use of pull-off bond tests to monitor the long-term bond performance of FRP-to-concrete interfaces, therefore would generally produce a safe, conservative assessment of the durability of FRP bonded concrete structures.

\section{Acknowledgements}

The authors gratefully acknowledge the financial support provided by the Grant-in-Aid for Young Scientists B, MEXT, Japan (Project No: 20760309) and by the General Research Fund (GRF) of Hong Kong SAR Government (Project Code: 516509). The authors would also like to thank the reviewers for their very constructive comments and Prof Jin-Guang Teng and Dr Lik Lam for their valuable discussion. In addition, the authors would like to appreciate the contribution of Nippon Steel Composite Co. Ltd, Japan for providing experimental materials and thank Mr Makoto Saito for providing valuable information relating to the properties of adhesive materials.

\section{REFERENCES}

Almusallam, T. H. (2006), Load-deflection behavior of RC beams strengthened with GFRP sheets subjected to different environmental conditions, Cement and Concrete Composites, 28, 879-889.

Au, C. and Büyüköztürk, O. (2006), Peeling and shear fracture characterization of debonding in FRP plated concrete affected by moisture, Journal of Composites for Construction, 10(1), 35-47.

Bank, L. C. and Gentry, T. R. (1995), Accelerated test method to determine the long-term behavior of FRP composite structures: environmental effects, Journal of Reinforced Plastics and Composites, 14, 559-587.

Chajes, M. J., Thomson, Jr. T. A. and Farschman, C. A. (1995), Durability of concrete beams externally reinforced with composite fabrics, Construction and Building Materials, 9(3), 141-148.

Dai, J.G, Sato, Y. and Ueda, T. (2002), Improving the load transfer and effective bond length for FRP composites bonded to concrete, Proceedings of the Japan Concrete Institute, 24(1), 1423-1428. 
Dai, J.G., Ueda, T. and Sato, Y. (2005), Development of the nonlinear bond stress-slip model of fiber reinforced plastics sheet-concrete interfaces with a simple method, Journal of Composites for Constructions, ASCE, 9(1), 52-62.

Dai, J.G., Yokota, H. and Ueda, T. (2009), A hybrid bonding system for improving the structural performance of FRP flexurally strengthened concrete beams, Advances in Structural Engineering, $12(6), 821-832$.

Davalos, J. F., Kodkani, S. S., Ray, I. and Boyajian, D. M. (2005), A fracture mechanics approach for interface durability of bond FRP to concrete, Proceedings of FRPRCS-7, ACI-SP-230-83, $1465-1480$.

Far, A. Al., Rostásy, F., Budelmann, H. and Hadid, T. Al. (2007), Durability of reinforced concrete members strengthened with CFRP plates and subjected to moisture and salts, Proceedings of the 8th International Symposium on Fiber-Reinforced Polymer Reinforcement for Concrete Structures (FRPRCS-8), CD-ROM, No.13-6, 16-18.

Grace, N. F. and Singh, S.B. (2005), Durability evaluation of carbon fiber-reinforced polymer strengthened concrete beams: experimental study and design, ACI Structural Journal, 102(1), 40-53.

Green, M. F., Bisby, L. A., Beaudoin, Y. and Labossiere, P. (2000), Effect of freeze-thaw cycles on the bond durability between fibre reinforced polymer plate reinforcement and concrete, Canadian Journal of Civil Engineering, 27(5), 949-959.

Jia, J., Boothy, Thomas E., Bakis, Charles E. and Brown, Tennisha L. (2005), Durability evaluation of glass fiber reinforced-polymer-concrete bonded interfaces, ASCE, Journal of Composites for Construction, 9(4), 348-359.

Karbhari, V. M. and Navada, R. (2008), Investigation of Durability and Surface Preparation Associated Defect Criticality of Composites Bonded to Concrete, Composites: Part A, 39, 997-1006.

Karbhari, V. M. and Zhao, L. (1998), Issues related to composite plating and environmental exposure effects on composite-concrete interface in external strengthening, Composite Structures, 40, 293-304.

Kobayashi, A., Tateishi, A. Sato, Y. and Takahashi, Y. (2009), Study on basic characteristics of FRP strand sheets and its flexural strengthening effect for RC beams, Proceedings of FRPRCS-9, 13-15, July, Sydney, Australia (CD-ROM). 
Leung, H., Balendran, R. and Lim, C. (2001), Flexural capacity of strengthened concrete beam exposed to different environmental conditions, Proceedings of the 1st International Conference on FRP Composites in Civil Engineering (CICE 2001), Hong Kong, China, 1597-1606.

Mukhopadhyaya, P., Swamy, R. N. and Lynsdale, C. J. (1998), Influence of aggressive exposure conditions on the behavior of adhesive bonded concrete-GFRP joints, Construction and Building Material, 12, 427-446.

Myers, J. J. and Ekenel, M. (2005), Effects of environmental conditions on bond strength between CFRP laminate and concrete substrate, Proceedings of FRPRCS-7, ACI SP-230-89, pp.1571-1592.

Ouyang, Z. and Wan, B. L. (2006), Numerical simulation of bond deterioration between CFRP plate and concrete in moisture environment, Proceedings of Third International Conference on FRP Composites in Civil Engineering (CICE2006), December 13-15 2006, Florida, USA, pp. 395-398.

Ouyang, Z. (2007), Durability of bond between FRP and concrete in moisture environments: experimental, numerical and analytical study, $\mathrm{Ph}$. D thesis submitted to Marquette University.

Saito M. (1996), United States Patent 5554672, Epoxy resin primer for lining of wet concrete surfaces, http://www.freepatentsonline.com/5554672.html.

Sen, R., Shahawy, M., Mullins, G., Spain, J. (1997), Durability of carbon fiber-reinforced polymer/epoxy/concrete bond in marine environment, ACI Structural Journal, 96(6), 906-914.

Silva, M. A.G. and Biscaia, H. (2008), Degradation of bond between FRP and RC beams, Composite Structures, 85, 164-174.

Teng, J.G., Chen, J.F., Smith, S.T. and Lam, L. (2002), FRP-Strengthened RC Structures, John Wiley and Sons Ltd, UK.

Toutanji, H. A., Gomez, W. (1997), Durability characteristics of concrete beams externally bonded with FRP composites sheets, Cement and Concrete Composites, 19(4), 351-358.

Wan, B., Petrou, Michael F. and Harries, Kent A. (2006), The effects of the presence of water on the durability of bond between CFRP and concrete, Journal of Reinforced Plastics and Composites, $25(8), 875-890$. 


\section{List of Figure Captions:}

Fig.1 Geometry of specimens for bending tests

Fig.2 Tensile pull-off bond tests

Fig.3 Carbon strand sheets

Fig.4 Comparison between a wet lay-up system and a CSS system

Fig.5 Tensile stress-strain curves of two different bonding adhesives

Fig.6 Degradation of interfacial tensile strength

Fig.7 Failed planes observed on pulled-off FRP composites

Fig.8 Microscopic observation on the FRP-to-concrete interfaces

Fig.9 Failure of FRP bonded concrete beams after bending tests

Fig.10 Effects of short-term moisture and primer on the shear failure of FRP-to-concrete interfaces

Fig.11 Effects of moisture on the short-term performance of FRP bonded concrete beams
a. effects of curing R.H. (dry substrate)
b. effects of curing R.H. (wet substrate)
c. effects of substrate moisture (normal primer)
d. effects of substrate moisture (hydrophobic primer)
e. effects of bonding adhesive (hydrophobic primer)

Fig.12 Effects of moisture on the long-term performance of FRP bonded concrete beams
a. B-1 series
b. B-6 series
c. B-7 series

Fig.13 Failure at the primer-to-concrete interface after wet/dry cycling

Fig. 14 Change of flexural capacity and maximum deflection over exposure time
a. B-1 series
b. B-6 series
c. B-7 series 


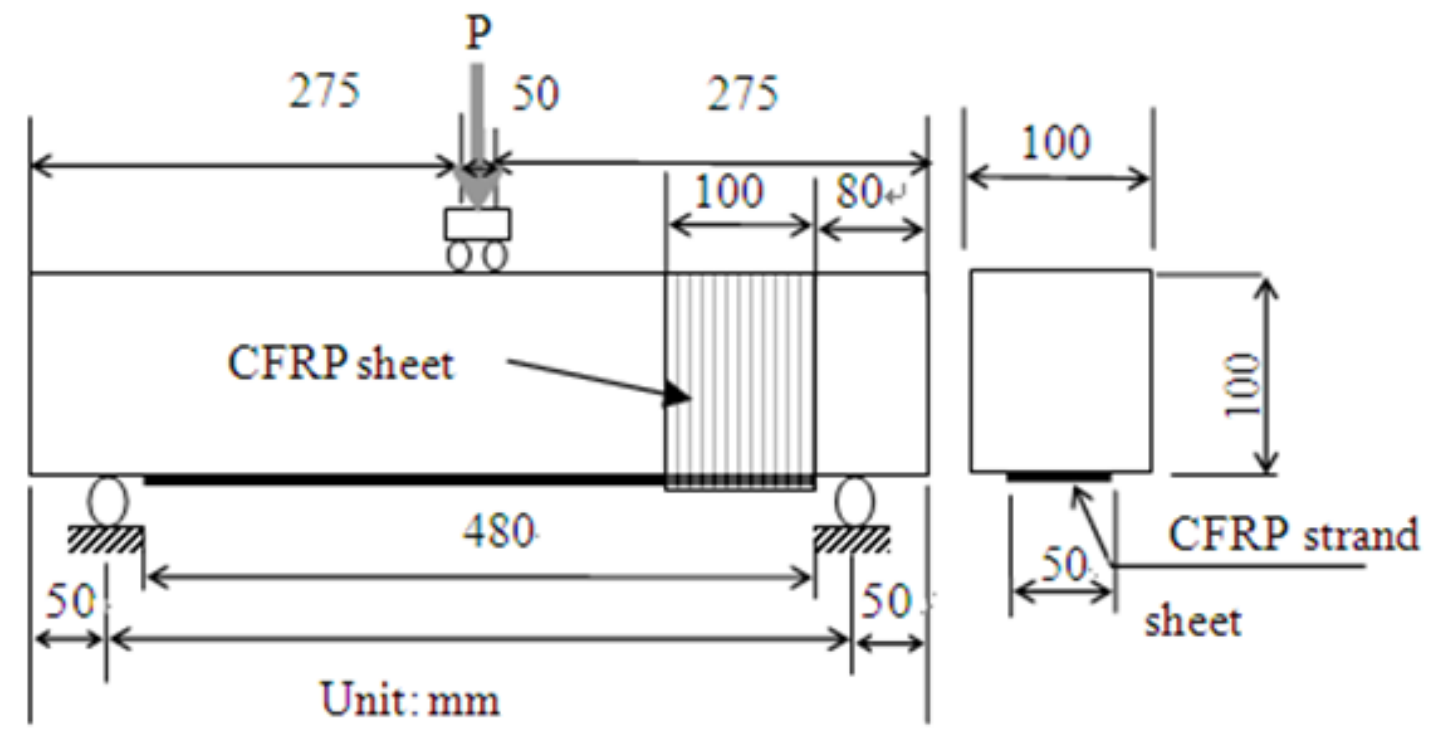

\section{Accepted Manuscript Not Copyedited}


Journal of Composites for Construction. Submitted November 16, 2009; accepted May 7, 2010; posted ahead of print May 12, 2010. doi:10.1061/(ASCE)CC.1943-5614.0000142

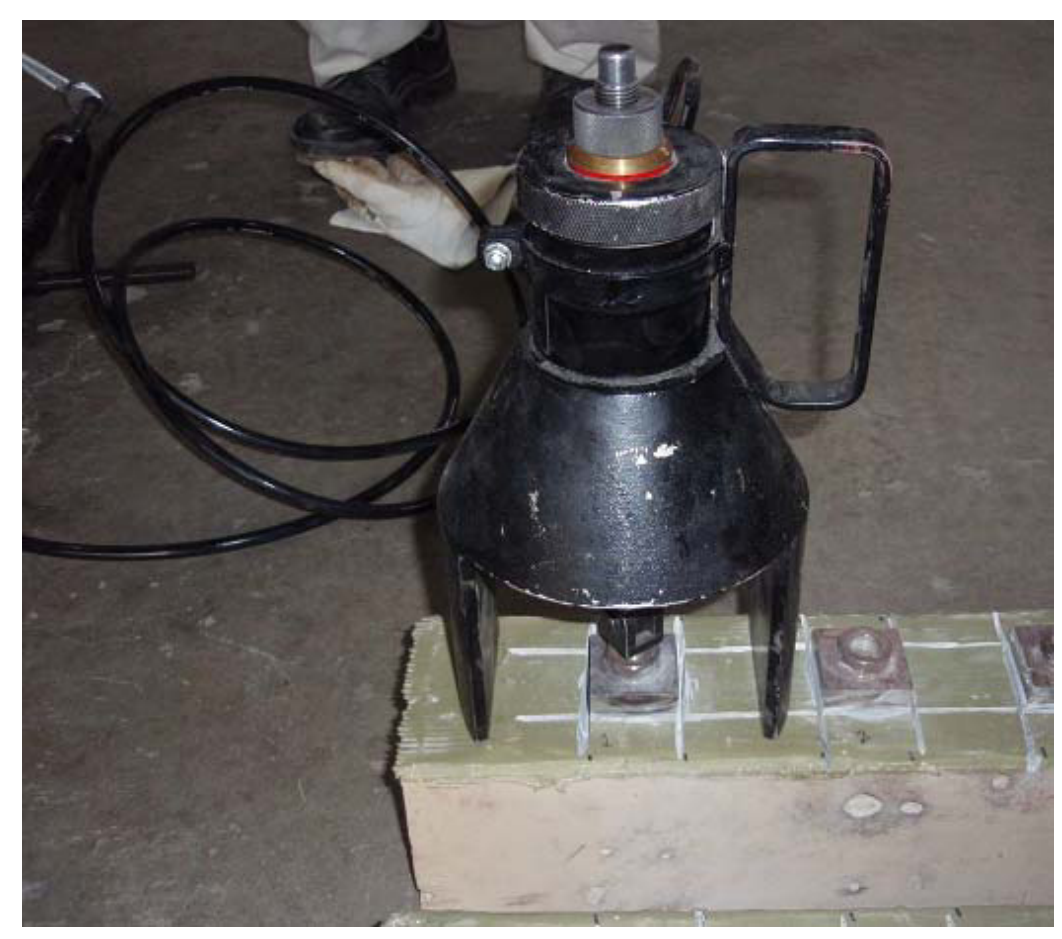

\section{Accepted Manuscript Not Copyedited}


Journal of Composites for Construction. Submitted November 16, 2009; accepted May 7, 2010; posted ahead of print May 12, 2010. doi:10.1061/(ASCE)CC.1943-5614.0000142

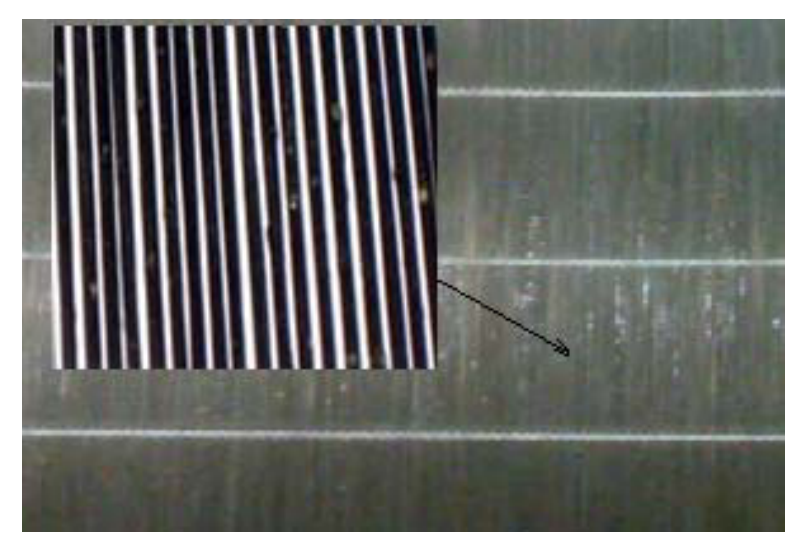

Accepted Manuscript Not Copyedited 
Dry carbon fibre sheet

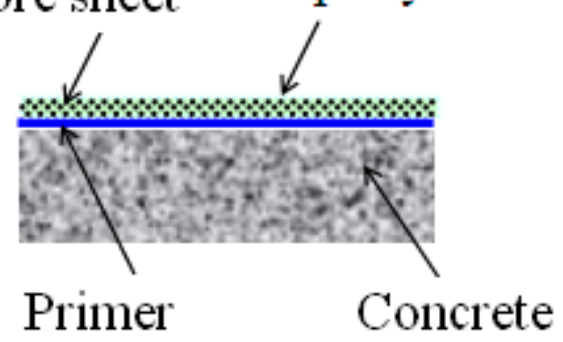

1. Wet lay-up system

Strand
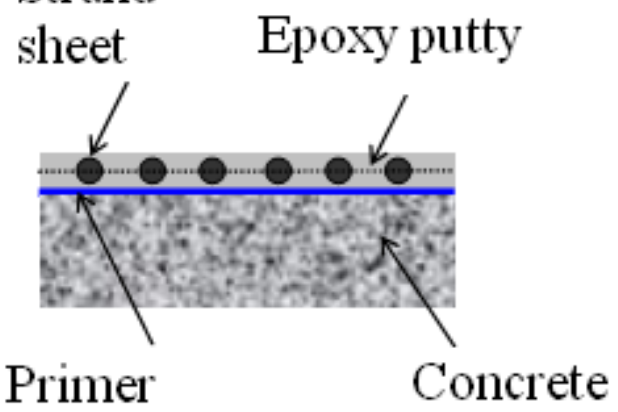

2. CSS system

\section{Accepted Manuscript Not Copyedited}


Journal of Composites for Construction. Submitted November 16, 2009; accepted May 7, 2010; posted ahead of print May 12, 2010. doi:10.1061/(ASCE)CC.1943-5614.0000142

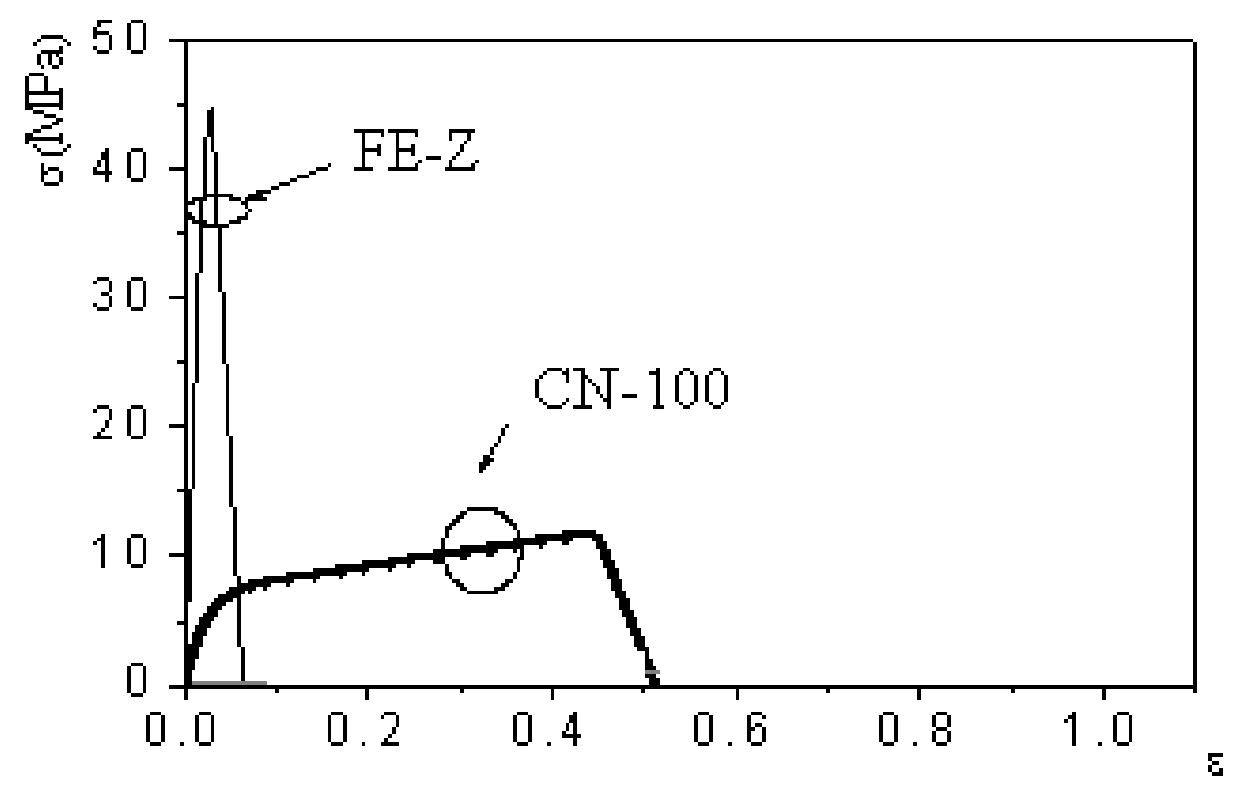

\section{Accepted Manuscript Not Copyedited}



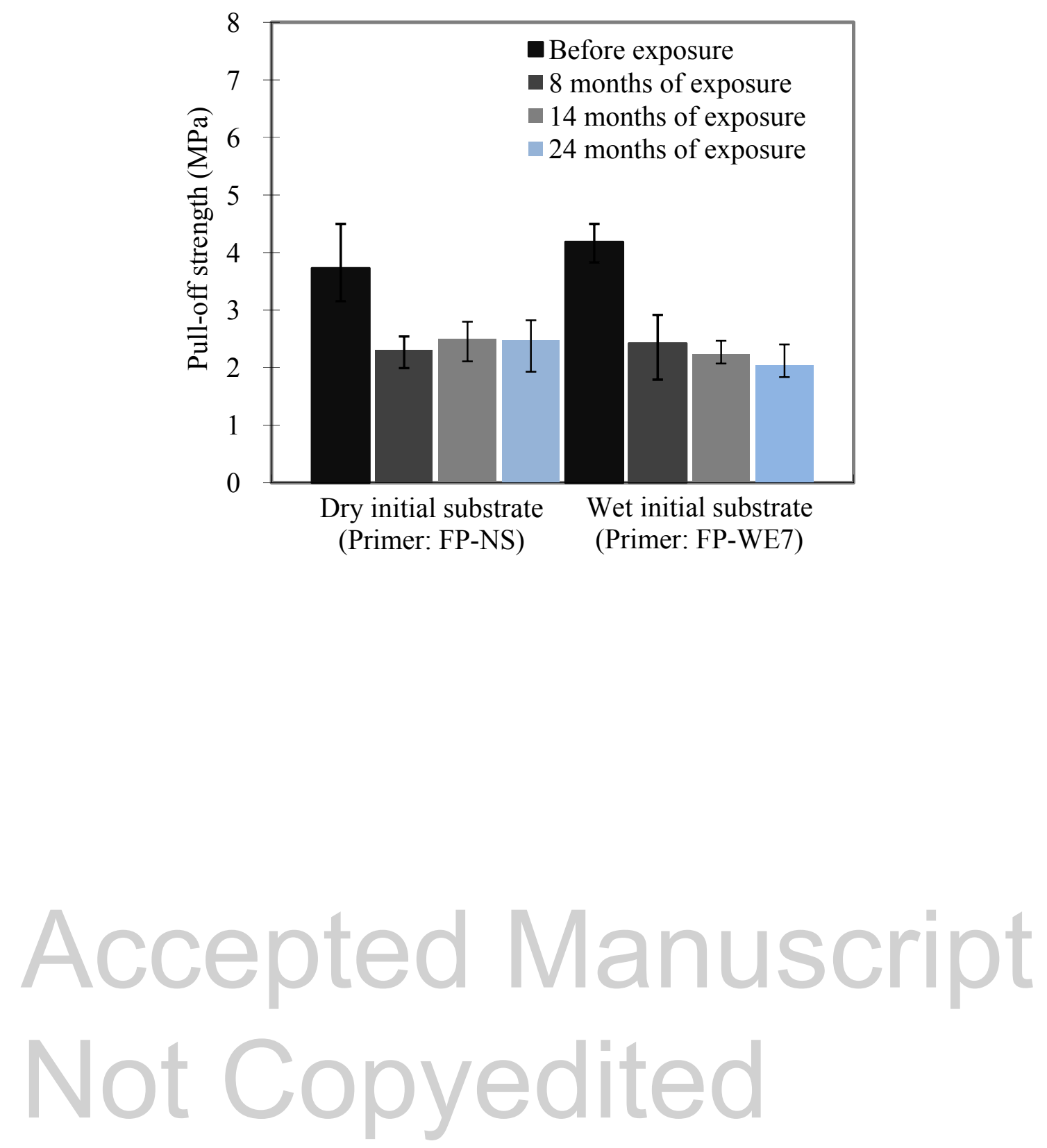

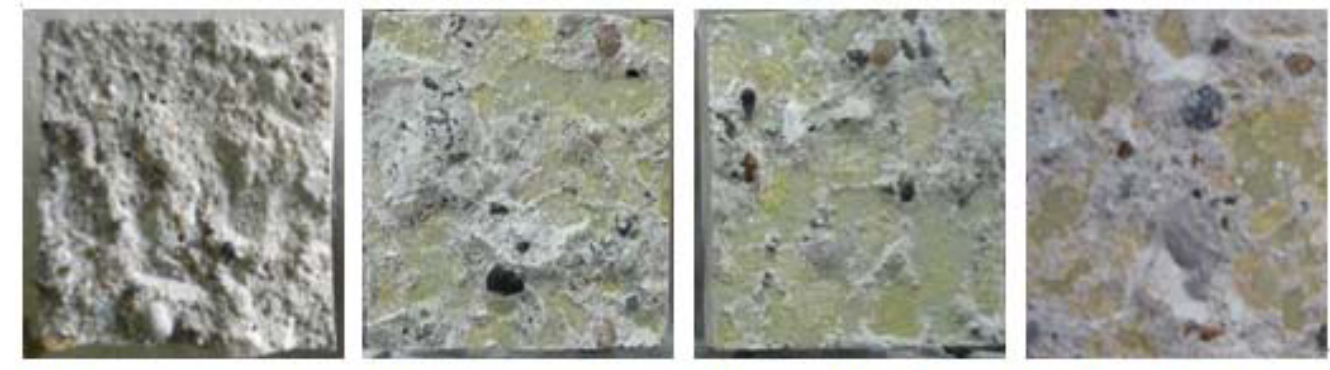

(before exposure) ( 8 months exposure) (14 months exposure) (2 years exposure)

Dry concrete substrate + primer FP-NS

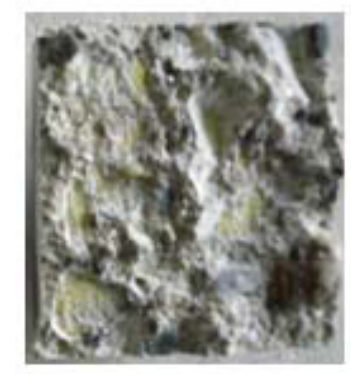

(before exposure)
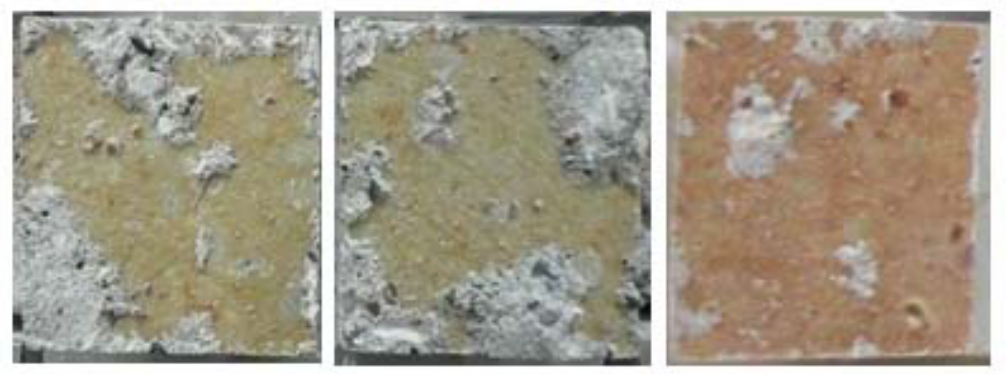

( 8 months exposure) (14 months exposure) ( 2 years exposure)

Wet concrete substrate + primer FP-WE7

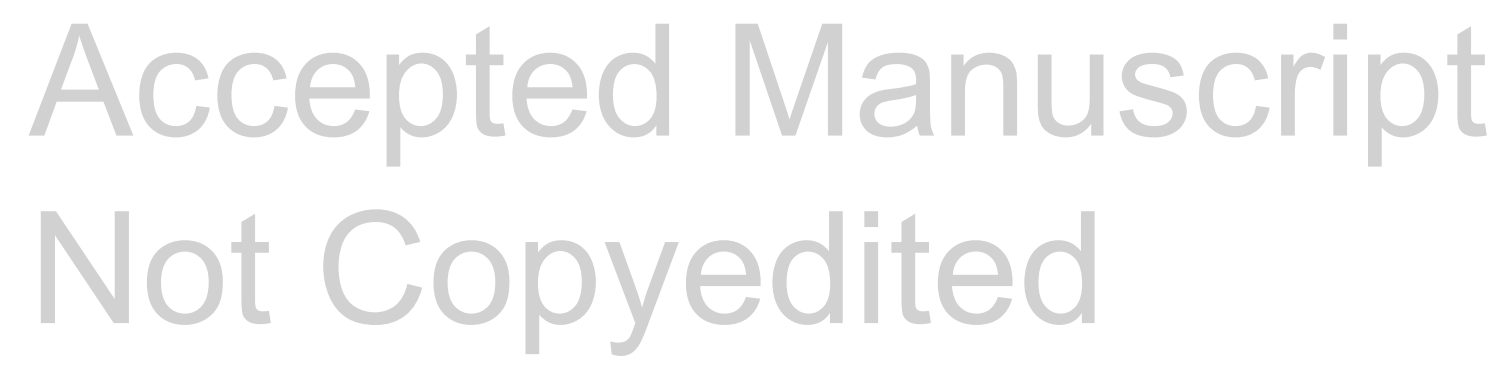




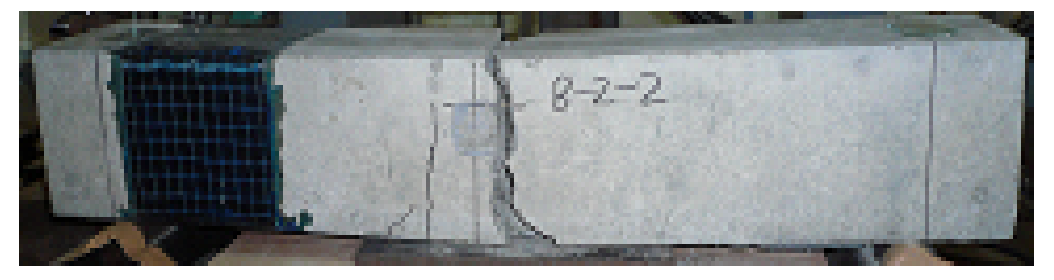

a: IC debonding

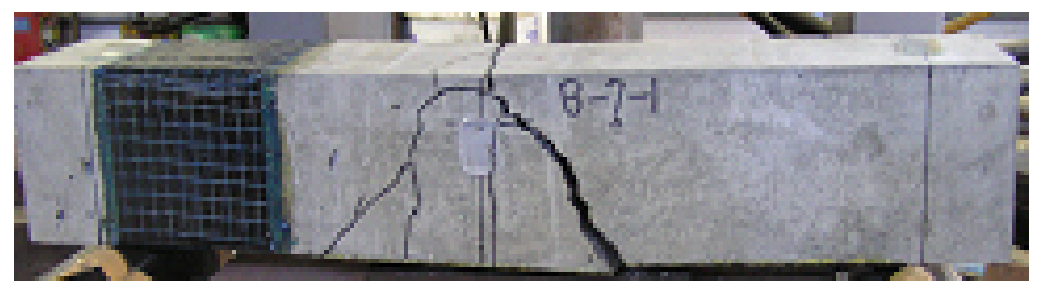

b: CDC debonding

\section{Accepted Manuscript Not Copyedited}


Journal of Composites for Construction. Submitted November 16, 2009; accepted May 7, 2010; posted ahead of print May 12, 2010. doi:10.1061/(ASCE)CC.1943-5614.0000142

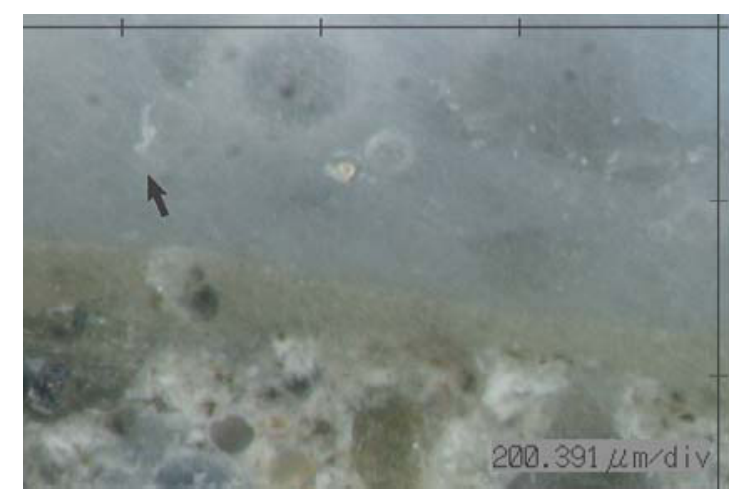

a. before exposure

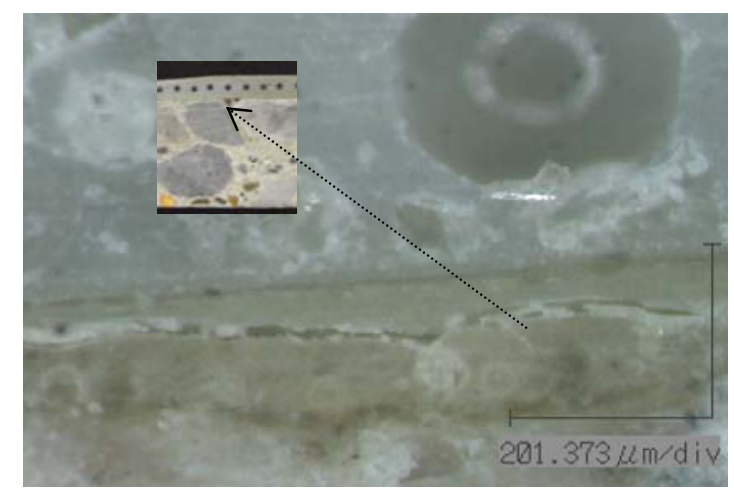

b. after exposure

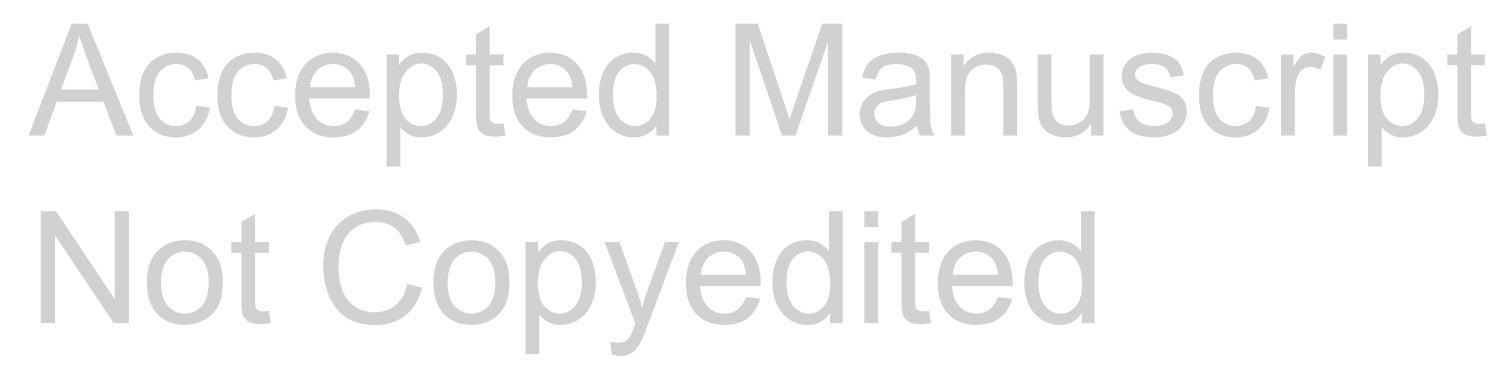



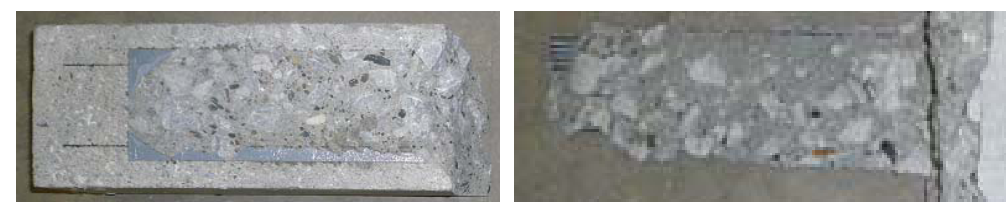

a. failure within concrete substrate (B-1 series)
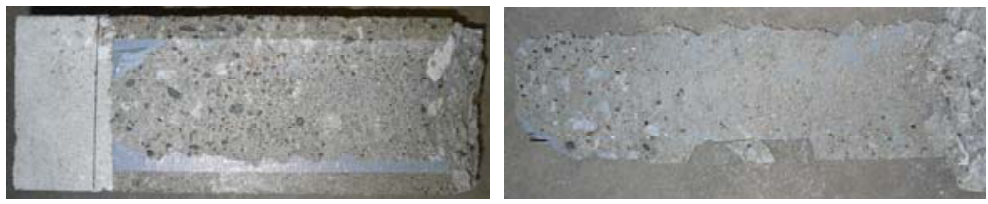

b. failure within concrete substrate (B-3 series)
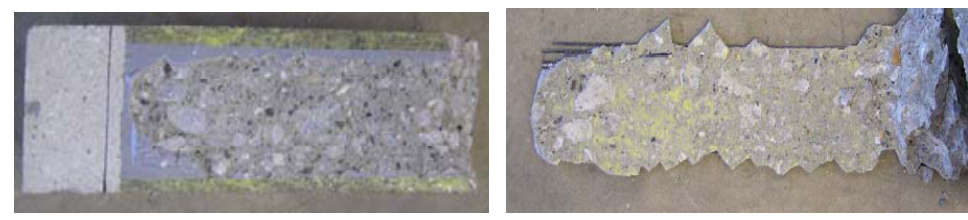

c. failure within concrete substrate (B-4 sereis)
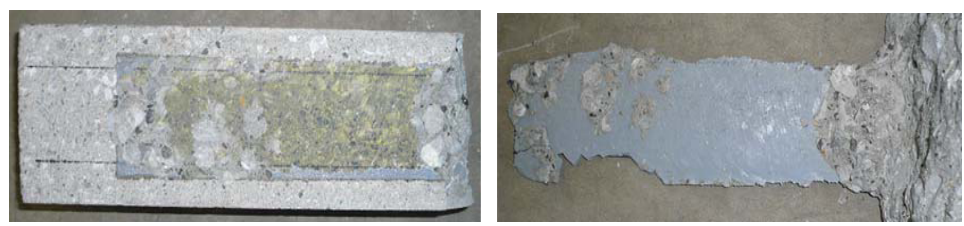

d. failure at primer to adhesive interface (B-2 series)
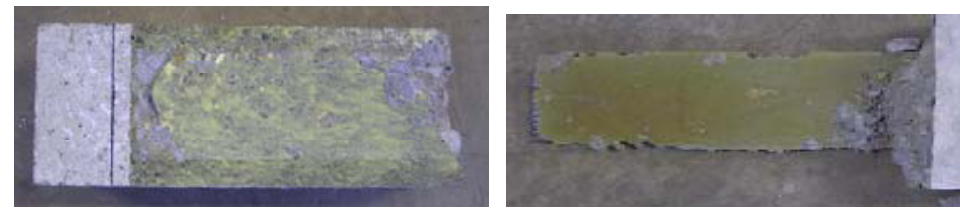

e. failure at primer to concrete interface (B-7 series)

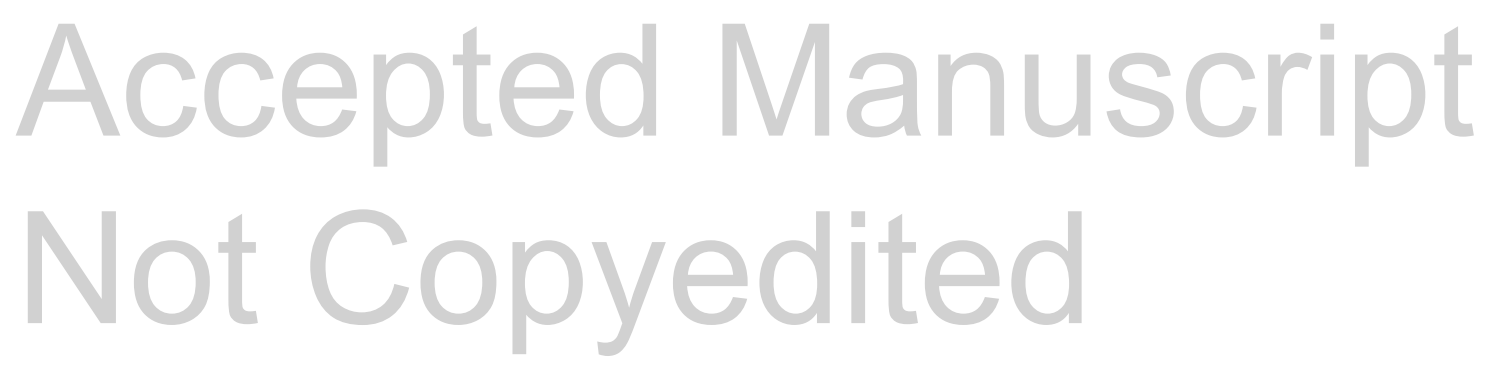




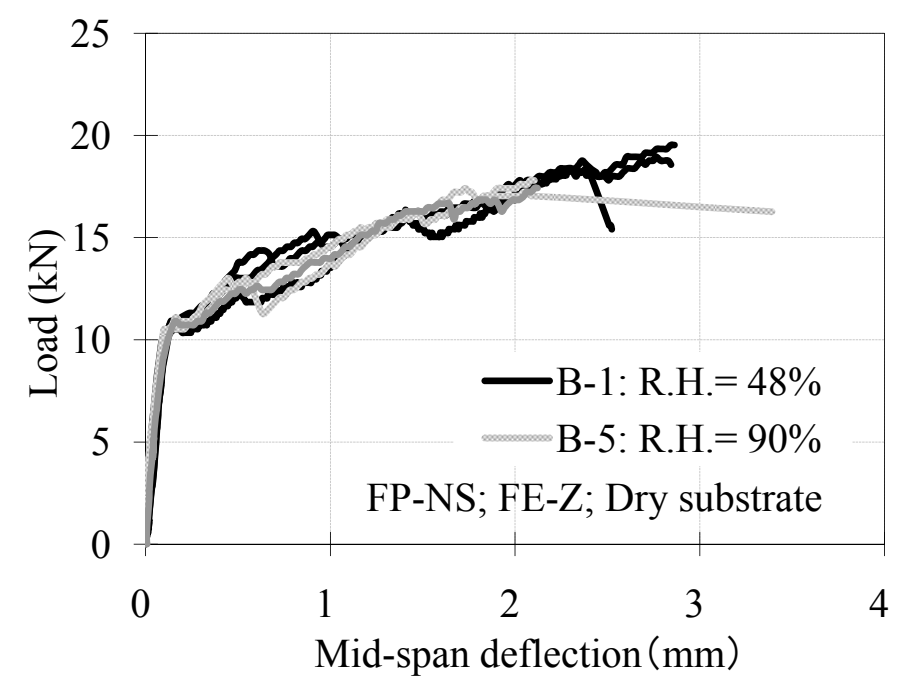

Accepted Manuscript
Not Copyedited 

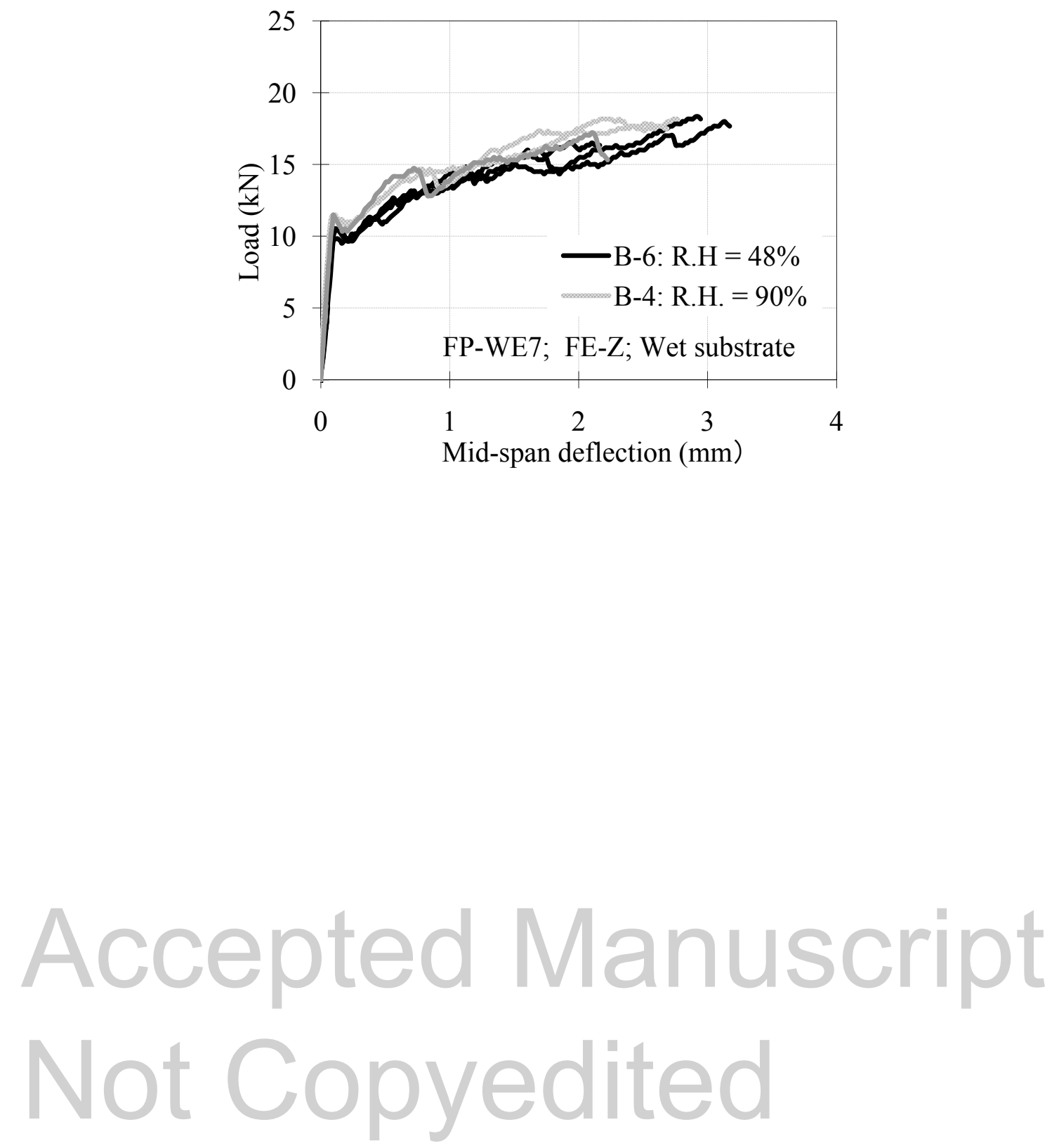


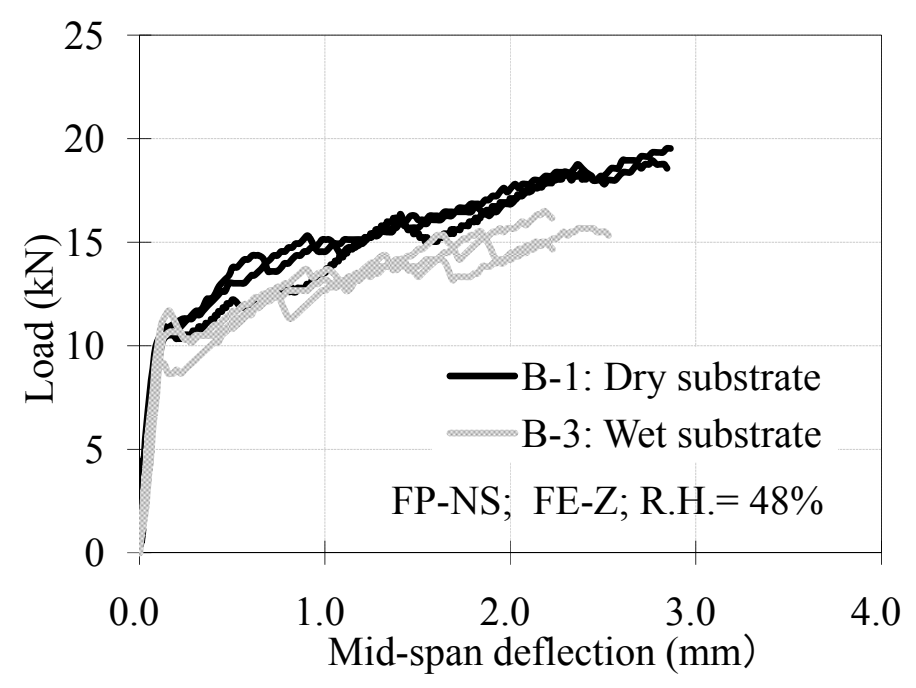

Accepted Manuscript
Not Copyedited 


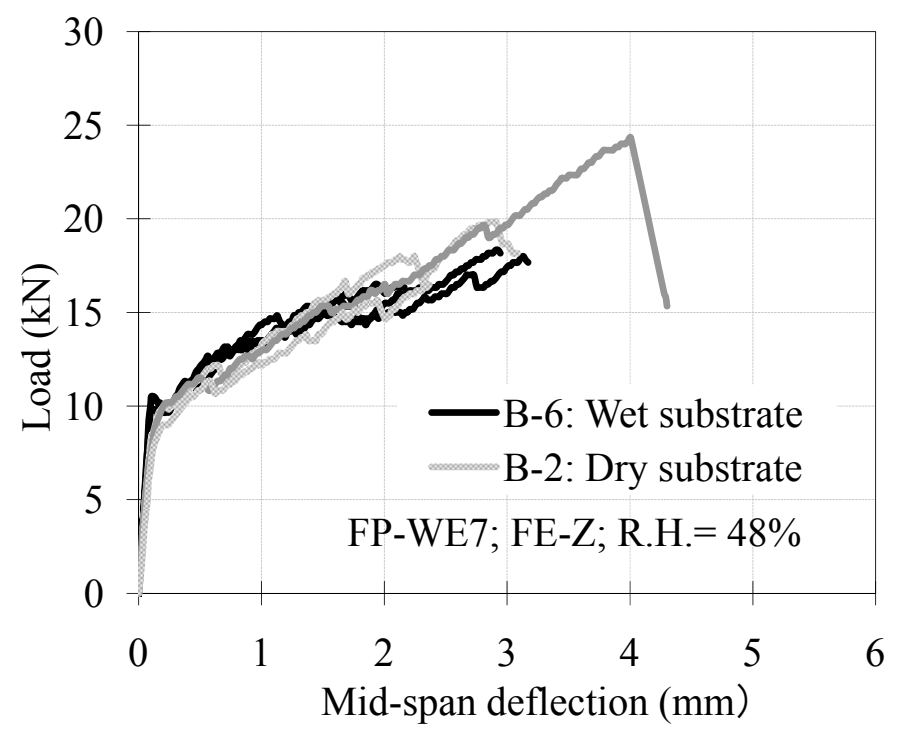

Accepted Manuscript
Not Copyedited 


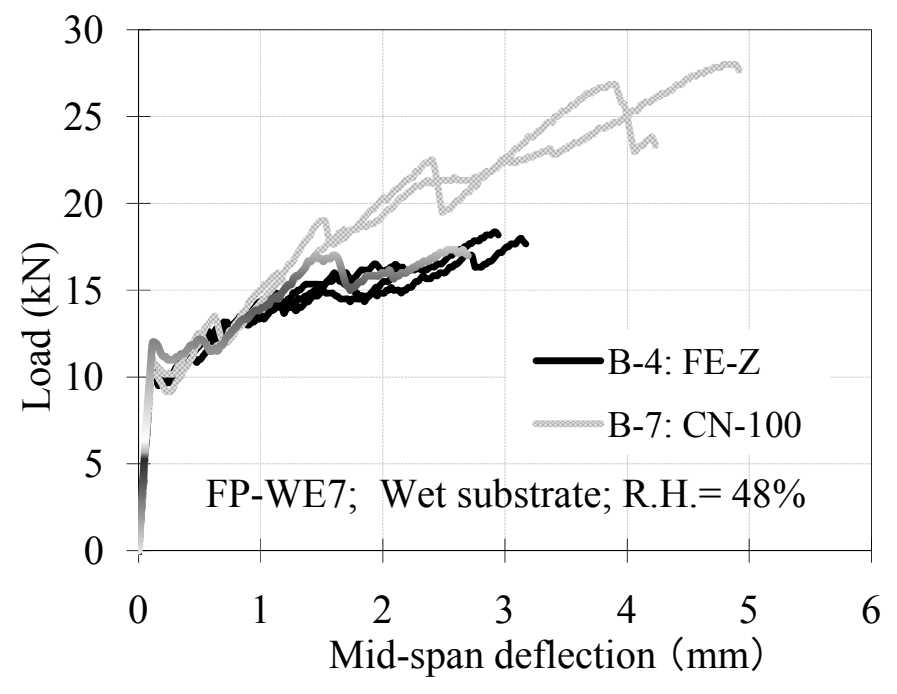

Accepted Manuscript
Not Copyedited 


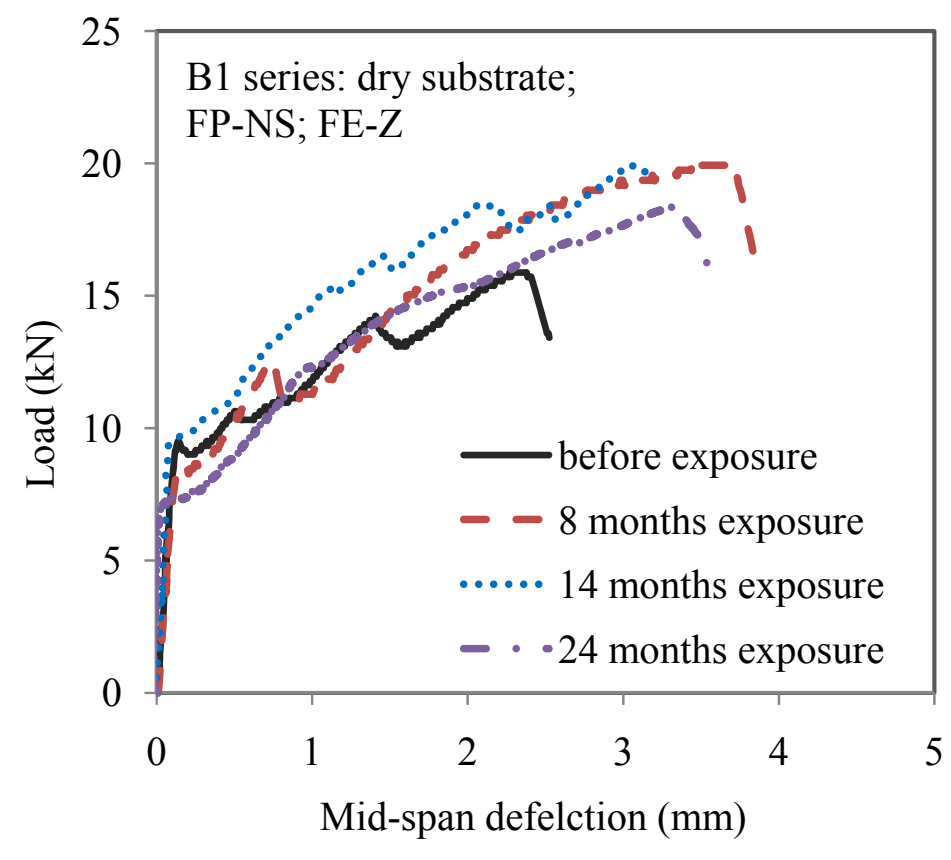

Accepted Manuscript
Not Copyedited 


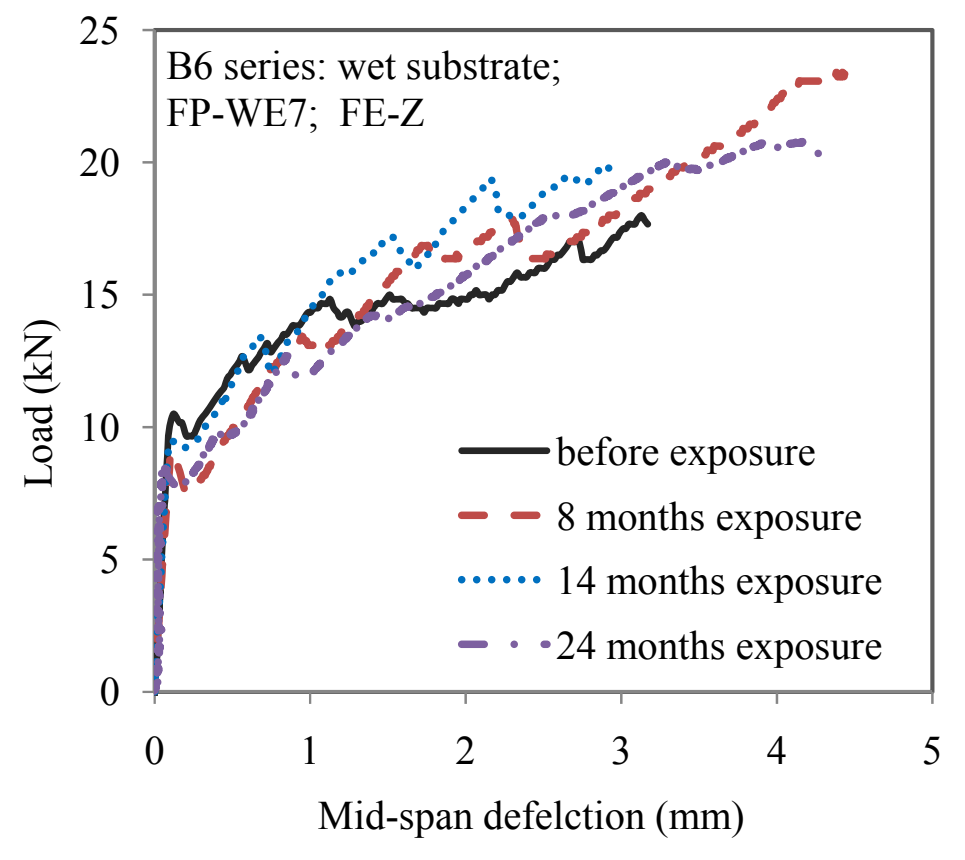

Accepted Manuscript
Not Copyedited 


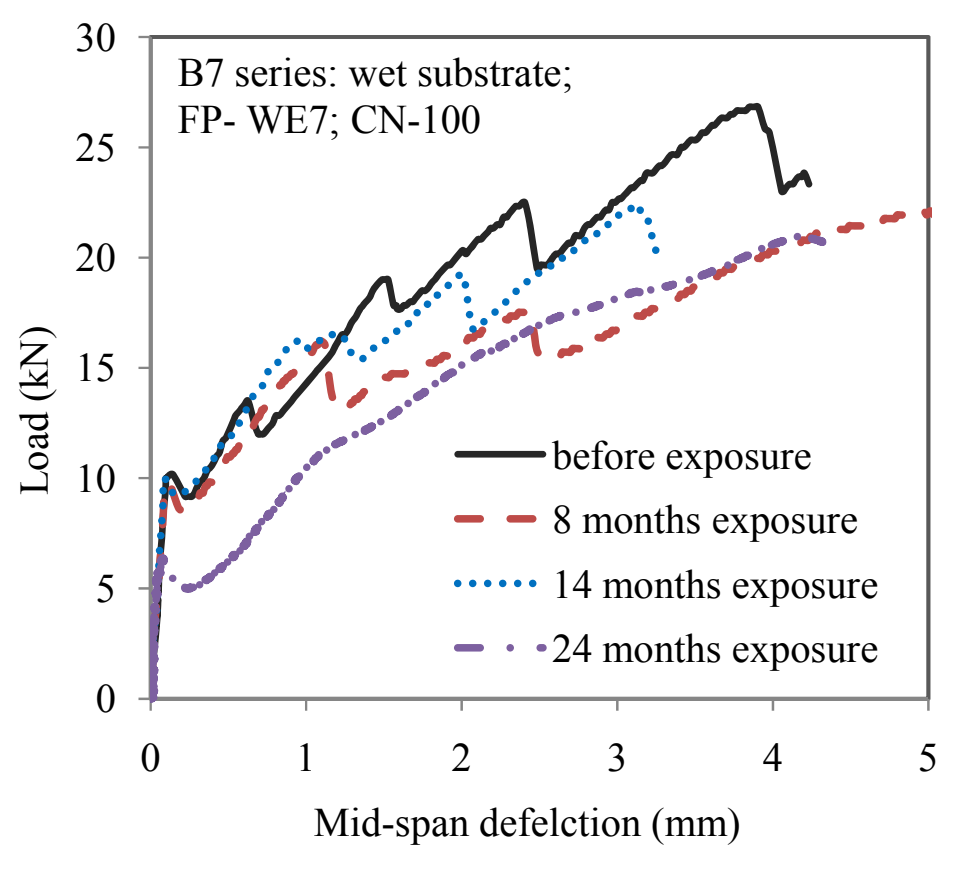

Accepted Manuscript
Not Copyedited 
Journal of Composites for Construction. Submitted November 16, 2009; accepted May 7, 2010; posted ahead of print May 12, 2010. doi:10.1061/(ASCE)CC.1943-5614.0000142

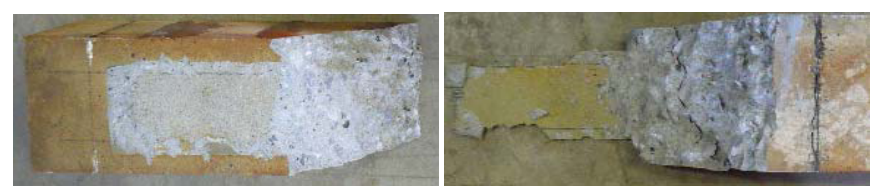

a. B-1 series

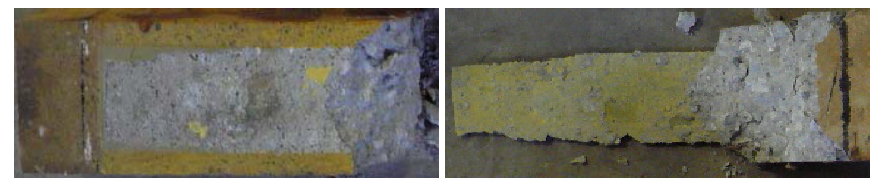

b. B-6 series

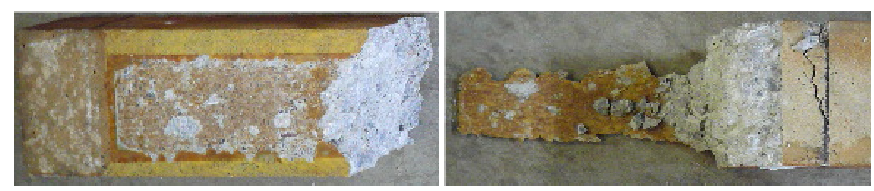

c. B-7 series

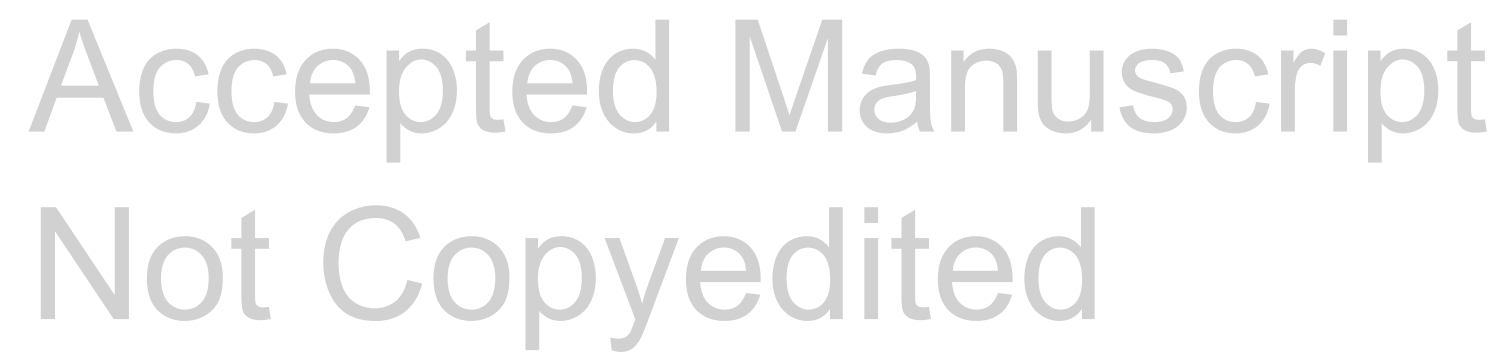




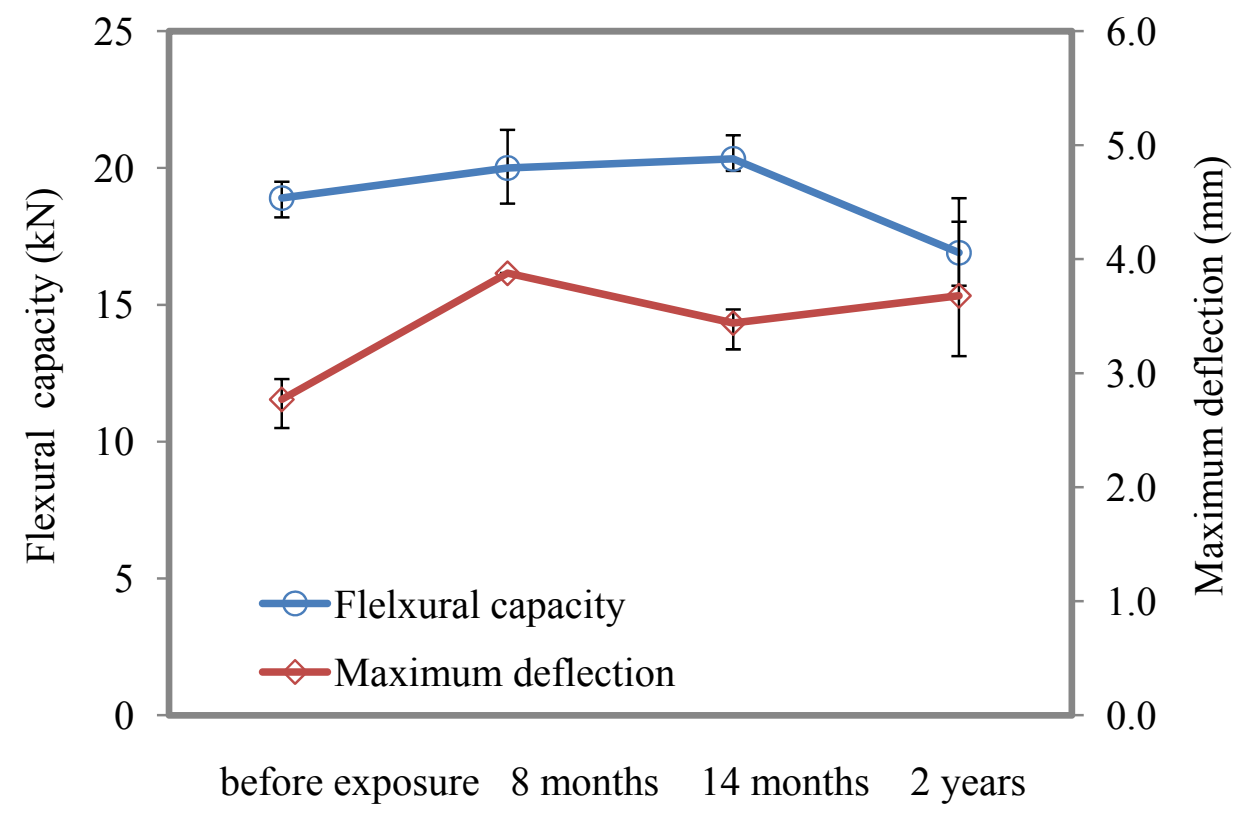

\section{Accepted Manuscript Not Copyedited}




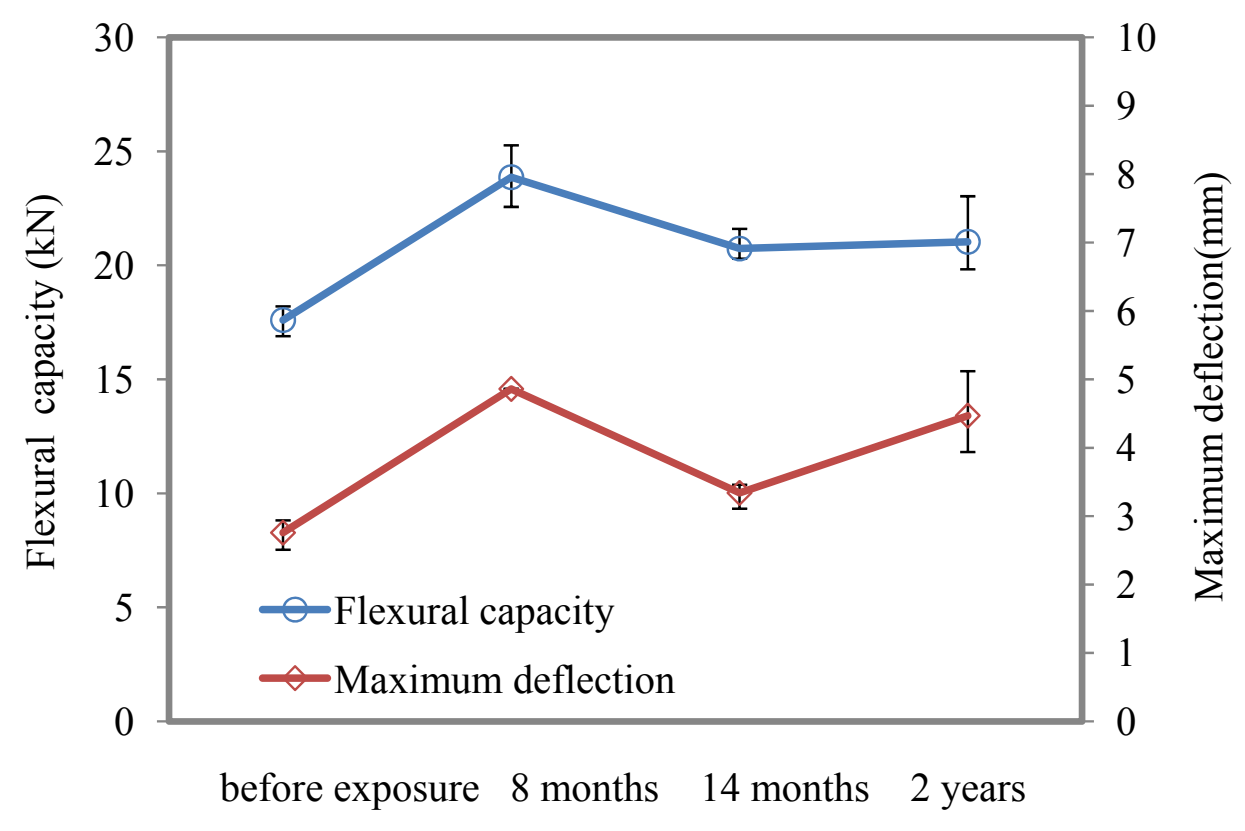

\section{Accepted Manuscript Not Copyedited}




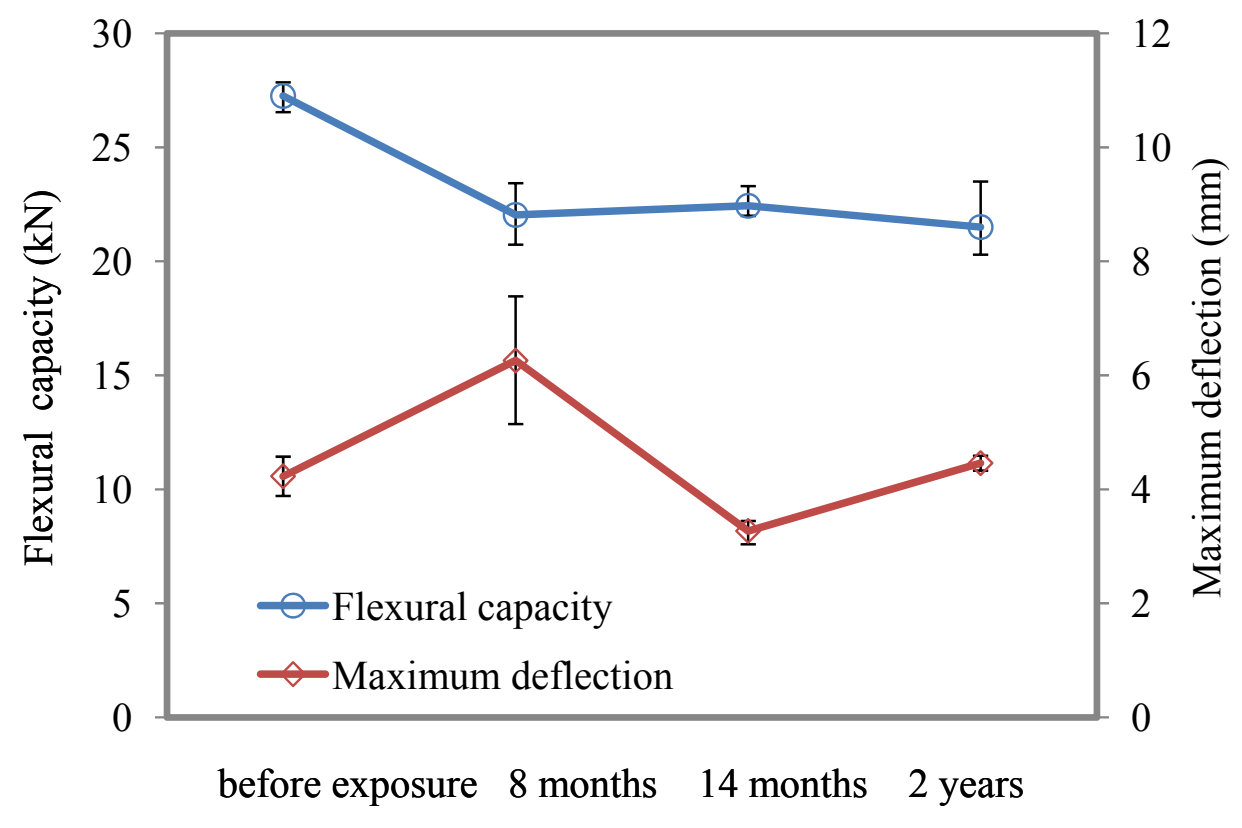

Accepted Manuscript
Not Copyedited 
Table 1 Summary of the information of specimens and test results.

\begin{tabular}{|c|c|c|c|c|c|c|c|c|c|c|c|c|}
\hline \multirow[b]{2}{*}{ Group } & \multirow[b]{2}{*}{ Code } & \multirow[b]{2}{*}{ Primer } & \multirow[b]{2}{*}{$\begin{array}{l}\text { Bonding } \\
\text { adhesive }\end{array}$} & \multirow[b]{2}{*}{$\begin{array}{l}\text { Substrate } \\
\text { condition }\end{array}$} & \multirow[b]{2}{*}{$\begin{array}{c}\text { Exposure } \\
\text { period } \\
\text { (months) }\end{array}$} & \multirow[b]{2}{*}{$\begin{array}{c}\text { Curing } \\
\text { R.H. (\%) }\end{array}$} & \multicolumn{4}{|c|}{ Bending test } & \multicolumn{2}{|c|}{ Pull-off test } \\
\hline & & & & & & & $\begin{array}{l}P_{\max } \\
(\mathrm{kN})\end{array}$ & $\begin{array}{r}\delta_{\max } \\
(\mathrm{mm})\end{array}$ & $\begin{array}{c}\text { Debond } \\
\text { ing } \\
\text { mode* }\end{array}$ & $\begin{array}{c}\text { Interface } \\
\text { failure } \\
\text { mode** }\end{array}$ & $\begin{array}{c}\sigma_{t b} \\
(\mathrm{MPa})\end{array}$ & $\begin{array}{l}\text { Failure } \\
\text { mode }\end{array}$ \\
\hline \multirow{21}{*}{ A } & B-1-1 & \multirow{3}{*}{ FP-NS } & \multirow{3}{*}{ FE-Z } & \multirow{3}{*}{ Dry } & \multirow{3}{*}{0} & \multirow{3}{*}{48} & 18.2 & 2.52 & IC & $\mathrm{A}$ & \multirow{3}{*}{3.73} & \multirow{3}{*}{ A } \\
\hline & B-1-2 & & & & & & 19.0 & 2.84 & IC & A & & \\
\hline & B-1-3 & & & & & & 19.5 & 2.95 & IC & $\mathrm{A}$ & & \\
\hline & B-2-1 & \multirow{3}{*}{ FP-WE7 } & & & & & 24.3 & 4.01 & $\mathrm{CDC}$ & $\bar{A}$ & & \\
\hline & B-2-2 & & FE-Z & Dry & 0 & 48 & 17.5 & 3.15 & IC & $\mathrm{C}$ & - & - \\
\hline & B-2-2 & & & & & & 19.8 & 3.08 & IC & $\mathrm{C}$ & & \\
\hline & B-3-1 & & & & & & 16.2 & 2.22 & IC & B & & \\
\hline & B-3-2 & FP-NS & FE-Z & Wet & 0 & 48 & 15.3 & 2.53 & IC & B & - & - \\
\hline & B-3-3 & & & & & & 14.7 & 2.23 & IC & B & & \\
\hline & B-4-1 & & & & & & 18.2 & 2.56 & IC & $\bar{B}$ & & \\
\hline & B-4-2 & FP-WE7 & FE-Z & Wet & 0 & 90 & 17.8 & 2.77 & IC & $\mathrm{B}$ & - & - \\
\hline & B-4-3 & & & & & & 17.3 & 2.69 & IC & $\mathrm{B}$ & & \\
\hline & B-5-1 & & & & & & 17.5 & 3.39 & IC & $\mathrm{A}$ & & \\
\hline & B-5-2 & FP-NS & FE-Z & Dry & 0 & 90 & 19.3 & 2.83 & IC & $\mathrm{A}$ & - & - \\
\hline & B-5-3 & & & & & & 17.5 & 2.41 & IC & $\mathrm{A}$ & & \\
\hline & B-6-1 & & & & & & 18.3 & 2.95 & IC & B & & \\
\hline & B-6-2 & FP-WE7 & FE-Z & Wet & 0 & 48 & 18.0 & 3.17 & IC & B & 4.19 & A \\
\hline & B-6-3 & & & & & & 16.5 & 2.16 & IC & $\mathrm{B}$ & & \\
\hline & B-7-1 & & & & & & 26.8 & 4.23 & CDC & $\mathrm{C}$ & & \\
\hline & B-7-2 & FP-WE7 & $\mathrm{CN}-100$ & Wet & 0 & 48 & 27.7 & 4.92 & $\mathrm{CDC}$ & $\mathrm{C}$ & - & - \\
\hline & B-7-3 & & & & & & 17.3 & 2.65 & IC & $\mathrm{C}$ & & \\
\hline & B-1-1-1 & & & & & & 19.9 & 3.87 & IC & $\mathrm{D}$ & & \\
\hline & B-1-1-2 & & & & 8 & & 21.4 & 388 & $\mathrm{CDC}$ & $\mathrm{D}$ & 2.31 & $\mathrm{~A} / \mathrm{B}$ \\
\hline & B-1-1-3 & & & & & & 18.7 & 3.88 & IC & $\mathrm{D}$ & & \\
\hline & B-1-2-1 & & & & & & 19.9 & 3.21 & $\mathrm{CDC}$ & $\mathrm{D}$ & & \\
\hline & B-1-2-2 & FP-NS & FE-Z & Dry & 14 & 48 & 21.2 & 3.56 & $\mathrm{CDC}$ & $\bar{D}$ & 2.51 & $\mathrm{~A} / \mathrm{B}$ \\
\hline & B-1-2-3 & & & & & & 19.9 & 3.55 & $\mathrm{CDC}$ & $\mathrm{D}$ & & \\
\hline & B-1-3-1 & & & & & & 16.1 & 3.15 & IC & $\mathrm{D}$ & & \\
\hline & B-1-3-2 & & & & 24 & & 18.9 & 4.33 & IC & $\mathrm{D}$ & 2.47 & $\mathrm{~A} / \mathrm{B}$ \\
\hline & B-1-3-3 & & & & & & 15.7 & 3.56 & IC & $\mathrm{D}$ & & \\
\hline & B-6-1-1 & & & & & & 25.4 & 5.08 & CDC & $\mathrm{D}$ & & \\
\hline & B-6-1-2 & & & & 8 & & 22.6 & 4.95 & $\mathrm{CDC}$ & $\mathrm{D}$ & 2.42 & $\mathrm{~A} / \mathrm{B}$ \\
\hline & B-6-1-3 & & & & & & 23.6 & 4.55 & CDC & $\mathrm{D}$ & & \\
\hline & B-6-2-1 & & & & & & 19.9 & 2.98 & $\mathrm{CDC}$ & $\mathrm{D}$ & & \\
\hline B & B-6-2-2 & FP-WE7 & FE-Z & Wet & 14 & 48 & 20.5 & 3.56 & CDC & $\mathrm{D}$ & 2.24 & $\mathrm{~A} / \mathrm{B}$ \\
\hline & B-6-2-3 & & & & & & 21.8 & 3.48 & $\mathrm{CDC}$ & $\mathrm{D}$ & & \\
\hline & B-6-3-1 & & & & & & 21.0 & 3.89 & CDC & $\mathrm{D}$ & & \\
\hline & B-6-3-2 & & & & 24 & & 21.9 & 5.23 & CDC & $\mathrm{D}$ & 2.05 & $\mathrm{~A} / \mathrm{B}$ \\
\hline & B-6-3-3 & & & & & & 20.2 & 4.29 & $\mathrm{CDC}$ & $\mathrm{D}$ & & \\
\hline & B-7-1-1 & & & & & & 22.1 & 6.53 & CDC & $\mathrm{D}$ & & \\
\hline & B-7-1-2 & & & & 8 & & 21.6 & 5.12 & $\mathrm{CDC}$ & $\mathrm{D}$ & - & - \\
\hline & B-7-1-3 & & & & & & 22.4 & 4.02 & CDC & $\bar{D}$ & & \\
\hline & B-7-2-1 & & & & & & 22.4 & 3.27 & CDC & $\mathrm{D}$ & & \\
\hline & B-7-2-2 & FP-WE7 & $\mathrm{CN}-100$ & Wet & 14 & 48 & 23.5 & 3.68 & CDC & $\mathrm{D}$ & - & - \\
\hline & B-7-2-3 & & & & & & 21.4 & 3.56 & $\mathrm{CDC}$ & $\mathrm{D}$ & & \\
\hline & B-7-3-1 & & & & & & 22.0 & 4.46 & IC & $\mathrm{D}$ & & \\
\hline & B-7-3-2 & & & & 24 & & 21.0 & 4.20 & $\mathrm{CDC}$ & $\mathrm{D}$ & - & - \\
\hline & B-7-3-3 & & & & & & 14.3 & 2.35 & IC & $\mathrm{C}$ & & \\
\hline
\end{tabular}

Note: $P_{\max }, \delta_{\max }=$ bending load and mid-span deflection of CSS bonded concrete beams at the ultimate state; $\sigma_{t b}=$ interfacial tensile pull-off strength (average of four tests); IC: intermediate crack-induced debonding; CDC: critical diagonal crack-induced debonding; A: failure in a thick concrete substrate; $\mathrm{B}$ : failure in a thin mortar layer; $\mathrm{A} / \mathrm{B}$ : failure as a combination of A and B; C: primer-to-adhesive interface failure; D: primer-to-concrete interface failure. 
Journal of Composites for Construction. Submitted November 16, 2009; accepted May 7, 2010; posted ahead of print May 12, 2010. doi:10.1061/(ASCE)CC.1943-5614.0000142

Table 2 Material properties of carbon strand sheet (CSS)

\begin{tabular}{|l|l|l|}
\hline Fiber density & $\rho_{f}\left(\mathrm{~g} / \mathrm{m}^{3}\right)$ & 400 \\
\hline Tensile strength & $f_{t}(\mathrm{MPa})$ & $>3400$ \\
\hline Elastic modulus & $E_{f}(\mathrm{GPa})$ & 245 \\
\hline Design thickness & $t_{f}(\mathrm{~mm})$ & 0.178 \\
\hline Section area of each strand & $A_{f}\left(\mathrm{~mm}^{2}\right)$ & 13.32 \\
\hline Tension stiffness & $E_{f} t_{f}(\mathrm{kN} / \mathrm{m})$ & 43.5 \\
\hline
\end{tabular}

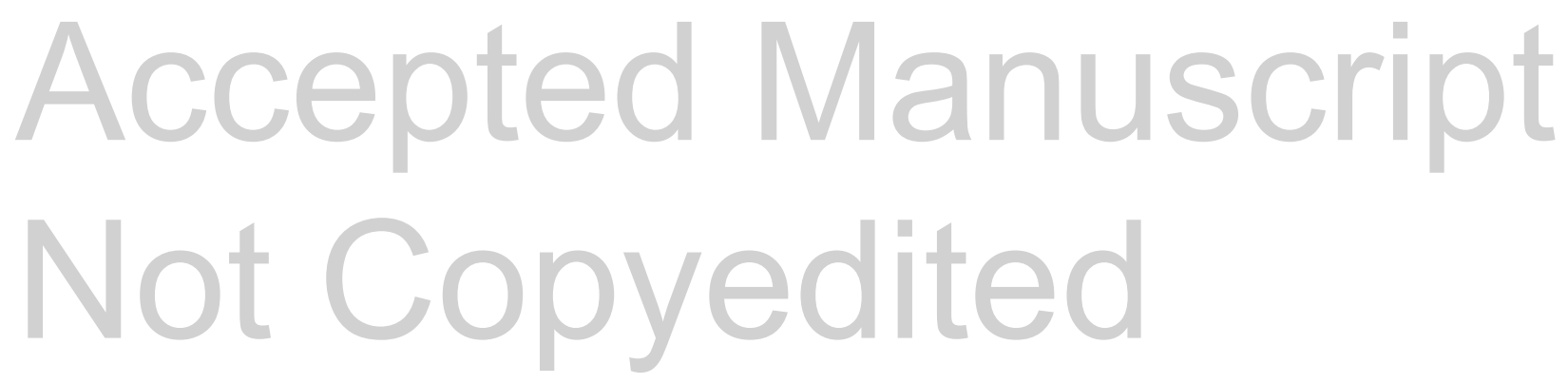

